\title{
Estudio de los macrorrestos vegetales de Praileaitz I (Deba, Gipuzkoa)
}

\author{
Praileaitz I (Deba, Gipuzkoa) landare-makrohondarren ikerketa
}

Study of plant macroremains from Praileaitz I (Deba, Gipuzkoa)

PALABRAS CLAVE: Paleolítico, Epipaleolítico, Paisaje forestal, Madera carbonizada, Semillas.

GAKO-HITZAK: Paleolitoa, Epipaleolitoa, Baso-paisaia, Zur ikaztua, Haziak.

KEYWORDS: Paleolithic, Epipaleolithic, Forest landscape, Charred wood, Seeds.

Mónica RUIZ-ALONSO(1), Lydia ZAPATA (†) ${ }^{(2)}$

\section{RESUMEN}

En este trabajo se presentan los resultados de los macrorrestos vegetales de la cueva de Praileaitz I. Se incluyen datos tanto antracológicos (carbón) como carpológicos (semillas y frutos). Los restos botánicos proceden tanto de estructuras de combustión como de materiales dispersos en el sedimento de la cueva. Se ha realizado una gran labor de recuperación en lo que a macrorrestos botánicos se refiere, procesando grandes cantidades de sedimento mediante flotación. De ahí que se haya recuperado una muestra importante de maderas. Así, el carbón mejor representado en las diferentes estancias y a lo largo de toda la secuencia antracológica, es el de Quercus caducifolio, acompañado por Juniperus sp. en algunos niveles. Junto a ellos el resto de taxones tienen una aparición meramente testimonial. Por el contrario, los restos carpológicos son prácticamente nulos.

\section{LABURPENA}

Lan honetan aurkezten dira Praileaitz I haitzuloko landareen makrohondarren emaitzak. Datu antrakologikoak (ikatza) nahiz karpologikoak (haziak eta fruituak) ere barne hartzen ditu. Aztarna botanikoak datoz errakuntza-egituretatik zein haitzuloko sedimentuan barreiatuta dauden materialetatik. Berreskuratze lan handia egin da makroaztarna botanikoei dagokienez, eta sedimentu ugari prozesatu da flotazioaren bidez. Horrela lortu da zur ugari berreskuratzea. Eta ikusi da alde batetik bai gela guztietan, bai sekuentzia antrakologiko guztian, Quercus hostoerorkorrarena dela ondoen ordezkatutako ikatza, Juniperus sp. maila batzuetan. Gainontzeko taxonak ozta-ozta agertzen dira. Bestetik, hutsaren hurrengo dira aztarna karpologikoak.

\section{ABSTRACT}

In this paper we present the results of the study of plant macroremains of the cave of Praileaitz I, including both charcoal and seeds and fruits. Those remains come from different structure combustion and materials scattered in the sediment of the cave. Since the beginning of the research proyect, we propose a great effort in order to recover all the botanical remains contained in the sediment, processing large amounts of sediment by the method of the flotation. Therefore, we have collected a large amount of remains. The main results show that the best represented charcoal in the all the different areas and along the whole sequence is deciduous Quercus, with Juniperus sp. in some levels. The other taxa reach very low values. In the case of the seeds and fruits, they are virtually absent.

\section{1.- INTRODUCCIÓN}

La cueva de Praileaitz I se sitúa en la orilla derecha del río Deba, en una pared vertical sobre su cauce, a una cota de 65 m.s.n.m. en el municipio guipuzcoano de Deba. Tras una entrada orientada al noreste de 2,50 m de anchura y 6 $\mathrm{m}$ de altura, se abren diferentes espacios: vestíbulo, galería noroeste, tránsito entre el vestíbulo y la primera sala interior, primera sala interior y segunda sala interior. Así mismo existe una pequeña plataforma en el exterior de la cavidad.

Los niveles culturales comprendidos en estos espacios abarcan entre el Epipaleolítico y el Gravetiense, si bien existe material de tipo musteriense en alguna de las zonas intervenidas. Así, el espacio exterior, pese a la escasez de restos, presenta una ocupación del Aziliense y otra del Magdaleniense Final, existiendo materiales asignables al inicio del Paleolítico Superior (35010 \pm 280 BP). El vestíbulo, la zona más iluminada dentro de la cavidad, cuenta con niveles pertenecientes al Epipaleolítico (10740 \pm 50 BP), al Magdaleniense Superior-Final (12920 \pm 50 $\mathrm{BP})$, al Magdaleniense Inferior (entre el $14700 \pm 100 \mathrm{BP}$ y el $15810 \pm 110 \mathrm{BP}$ ) y al Solutrense (entre el $17850 \pm 70$ BP y el $19330 \pm 150 \mathrm{BP}$ ). La galería noroeste presenta características específicas, principalmente en los niveles

\footnotetext{
(1) G. I. Arqueobiología. Instituto de Historia. Centro de Ciencias Humanas y Sociales (CCHS). Consejo Superior de Investigaciones Científicas (CSIC). C/Albasanz 26-28, 28037, Madrid. moruizalonso@hotmail.com

(2) En el proceso de publicación de este documento hemos perdido a uno de sus autores. Lydia Zapata era una investigadora brillante, pero brillaba más como amiga.
} 
inferiores, al haberse producido un aporte de materiales procedentes de una galería perpendicular a esta, colmatada en su momento y hoy en curso de excavación. Es por ello que en esta zona se ha detectado tan solo de forma clara en nivel de empedrado del Magdaleniense Inferior fechado en torno al $15500 \mathrm{BP}$, existiendo un paquete de sedimento por encima de él y otro por debajo. El superior, con escasos materiales, abarcaría entre el Epipaleolítico y el Magdaleniense Inferior, mientras que el inferior cuenta con algunos restos de tipología musteriense, además de una datación del $25320 \pm 140$ BP, de procedencia, muy probablemente de la galería colmatada. El tránsito entre el vestíbulo y la primera sala interior cuenta con niveles del Epipaleolítico (hogares datados en el $8940 \pm 50$ BP y caracoles marinos), del Magdaleniense Superior-Final, del Magdaleniense Inferior y del Solutrense. En la primera sala interior están representados el Epipaleolítico, con un hogar intrusivo en el nivel inferior $(8840 \pm 45$ y $8845 \pm 40$ $\mathrm{BP})$, el Magdaleniense Inferior, con numerosos colgantes líticos y el Solutrense, del que apenas se ha excavado su parte más superficial. La segunda sala interior cuenta con 9 niveles diferenciados, 8 de los cuales corresponden al Epipaleolítico, con dataciones entre el $8800 \pm 35$ BP y el $9225 \pm 40$ BP. El nivel IX está asociado a materiales solutrenses y ha sido datado en el $17530 \pm 70 \mathrm{BP}$

Algunas de las numerosas dataciones realizadas en Praileaitz I se han realizado sobre madera carbonizada. En su mayoría, y desde que los trabajos sobre macrorrestos vegetales se integraron en el equipo de investigación, han sido identificadas anatómicamente con anterioridad a su envío para la datación. Estas se han identificado como madera perteneciente a Quercus subgénero Quercus exceptuando un fragmento no determinable.

La vegetación potencial en el entorno cercano del yacimiento, según Aseguinolaza et al. (1992), reflejaría cómo en los lugares alejados del cauce fluvial se desarrollarían los encinares cantábricos, que tienen un carácter marcadamente mediterráneo, y se establecen sobre suelos secos, en exposiciones soleadas, mostrando preferencia por los sustratos básicos, aunque no se han recuperado restos entre las maderas conservadas. Entre las plantas más características que acompañan al encinar están Phyllyrea latifolia, Smilax aspera, Rosa sempervirens, Arbutus unedo y Hedera Helix, entre otras. También, en el entorno de Praileaitz I sobre pisos colinos, se localizaría potencialmente un robledal acidófilo y robledal-bosque mixto atlántico. Estos bosques, de dominio del roble pedunculado, pueden ser de dos tipos. Los primeros se desarrollan sobre suelos fuertemente ácidos de ladera, con agrupaciones de plantas acidófilas como Blechnum spicant, Dryopteris dilatata, Hypericum pulchrum, etc, junto a algunos arbustos y arbolillos como llex aquifolium, Betula celtiberica o Pyrus cordata. El segundo tipo es el desarrollado sobre sustratos básicos y suelos próximos a la neutralidad. Aquí destaca la presencia de gran variedad de árboles y arbustos como Corylus avellana, Acer campestre, Ulmus glabra, Salix atrocinera, entre otros, con un estrato herbáceo también muy variado. En el entorno de los cursos de agua dulce se desarrollaría una aliseda cantábrica, en la que el Alnus es el árbol por excelencia, formando bosques de galería condicionados por el encharcamiento del suelo.

En la actualidad, además de pequeñas manchas de la vegetación anteriormente mencionada, como el encinar cantábrico o fragmentos de aliseda, más o menos alterados, la vegetación del entorno se ha visto modificada. En primer lugar, por las diferentes plantaciones que se han localizado, en el entorno más o menos cercano de la cueva, en su mayoría de Pinus radiata, y en segundo lugar, por la presencia de una cantera en el mismo lugar en el que se localiza Praileaitz I, con zonas totalmente alteradas o humanizadas y de vegetación casi inexistente.

\section{2.- MATERIAL Y MÉTODO}

\subsection{Desarrollo del muestreo}

En el yacimiento arqueológico de Praileaitz I, durante el desarrollo de la excavación, se localizaron maderas carbonizadas de dos formas bien diferenciadas. En primer lugar los carbones concentrados en estructuras de combustión (4 en concreto) y en segundo lugar aquellos que se encuentran dispersos en el sedimento de la cueva. Así, se ha llevado a cabo un muestreo arqueobotánico exhaustivo. Se cuenta con dos tipos de muestras: 1) de sedimento procedente de las diferentes estancias, niveles y lechos localizados en Praileaitz I, que posteriormente ha sido procesado mediante flotación y 2) recogidas puntuales de macrorrestos vegetales aislados, identificados y recolectados in situ durante el transcurso de la excavación, normalmente con coordenadas. Ambos métodos combinados aseguran una excelente recuperación de los macrorrestos arqueológicos y bioarqueológicos contenidos en el sedimento. Sin este procesado, los macrorrestos vegetales difícilmente serían recuperados, ya que los de menor tamaño pueden pasar desapercibidos, recogiéndose únicamente los de mayor tamaño (frecuentemente bellotas, avellanas, etc.) o las acumulaciones de estos (madera carbonizada en hogares, concentraciones de frutos o semillas, etc.). A lo largo de todo el proceso, tanto en la recuperación, como en la posterior identificación y procesado de los datos, se ha tenido en cuenta que en Praileaitz I se localizan carbones dispersos en el sedimento o concentrados en diferentes estructuras de combustión, manteniéndose siempre las muestras individualizadas.

Se ha realizado un muestreo sistemático que ha contemplado la totalidad de las zonas de intervención excavadas hasta el momento de la publicación de este texto, es decir, el vestíbulo, la galería noroeste, el tránsito entre el vestíbulo y la primera sala interior (o pasillo), la primera sala interior y la segunda sala interior, aunque no todas están representadas de la misma manera (Tabl. 1). Se han estudiado un total de 3448 muestras. De estas, 329 son de sedimento procesado por flotación y el resto, 3119 , son elementos carbonizados puntuales recogidos en el yacimiento, y que se han tomado de forma individualizada. De todas ellas, 213 se han recuperado del 
Vestíbulo (154 de flotación y 59 elementos individualizados), 256 del Pasillo (zona de tránsito entre el vestíbulo y la primera sala interior), de las cuales 98 son de flotación y 158 elementos individualizados. De la Sala Interior proceden 145 muestras (76 de flotación y 69 elementos individualizados), de la segunda sala interior provienen 2829, la mayor concentración de todo el yacimiento (una sola procesada por flotación), y por último, de la galería noroeste se han estudiado solamente 5 muestras, todas ellas recogidas a mano.

En el caso del sedimento tratado con máquina de flotación, se han procesado un total de 329 muestras de sedimento. Como ya se ha comentado, se han tomado en todos los lechos excavados en la cueva, con la excepción

\begin{tabular}{|l|c|c|c|c|c|c|}
\hline \multicolumn{1}{|c|}{ MUESTRAS } & VESTÍBULO & $\begin{array}{c}\text { GALERÍA } \\
\text { NOROESTE }\end{array}$ & PASILLO & $\begin{array}{c}1^{\text {a }} \text { SALA } \\
\text { INTERIOR }\end{array}$ & $\begin{array}{c}2^{\text {a SALA }} \\
\text { INTERIOR }\end{array}$ & TOTAL \\
\hline FLOTACIÓN & 154 & - & 98 & 76 & 1 & 329 \\
\hline $\begin{array}{l}\text { ELEMENTOS } \\
\text { INDIVIDUALIZADOS }\end{array}$ & 59 & 5 & 158 & 69 & 2828 & 3119 \\
\hline TOTAL & 213 & 5 & 256 & 145 & 2829 & $\mathbf{3 4 4 8}$ \\
\hline
\end{tabular}

Tabl. 1. Distribución de las muestras recuperadas para el estudio de macrorrestos botánicos $(n=3448)$. / Distribution of recovered samples for the study of botanical macroremains $(n=3448)$.

de la galería noroeste. El volumen procesado por cada muestra ha variado, dependiendo del volumen excavado en cada lecho, entre los 0,1 y los 3 litros de manera general, procesándose un total de 635,58 litros. Esta técnica ofrece varias ventajas como el procesado de un gran volumen de sedimento de forma rápida, lo que permite, en yacimientos que no son muy ricos en macrorrestos, recuperar semillas, frutos o carbones que de otra forma no serian visibles. La flotación con máquina es en realidad un sistema de criba de agua, lo que permite recuperar todo tipo de materiales, debido al pequeño tamaño de la luz de las mallas utilizadas $(0,5 \mathrm{~mm})$, favoreciendo la recuperación de todos los restos como la microfauna, restos líticos, etc. (MARINVAL, 1986; WAGNER, 1988; BUXÓ, 1990, 1997; DE MOULINS, 1996; ALONSO MARTÍNEZ, 1999; ALONSO MARTÍNEZ et al., 2003; BUXÓ \& PIQUE, 2003, 2008; ZAPATA \& PEÑA- CHOCARRO, 2013). La flotación separa los restos por densidades. El agua ayuda a que el sedimento se deshaga, las partículas pesadas se depositan en el fondo y el material más ligero, carbonizado, flota. La máquina que se ha utilizado está compuesta por un bidón, en este caso con una capacidad aproximada de 200 litros, una entrada de agua a media altura y un rebaje superior. El agua entrante se distribuye por el recipiente a través de una retícula de tubos agujereados. El agua en movimiento permite que la tierra se filtre a través de la malla que se sitúa en el tercio superior. Las piedras y los restos arqueológicos quedan atrapados en la malla interior -en Praileaitz I, de 0,5 mm para recuperar la microfauna-, mientras que los carbones de madera y otros restos de menor densidad flotan y, cuando el agua rebosa, caen por la lengüeta, recuperándose en la malla exterior de $0,25 \mathrm{~mm}$.

Una vez finalizado este proceso, la muestra se ha secado a la sombra, a temperatura ambiente, para evitar una deshidratación brusca que pudiera fragmentar los restos. Se ha etiquetado y trasladado al laboratorio, donde se ha procedido a su identificación. El residuo de la flotación, formado por el material recuperado en la malla interior, se ha examinado en tres fracciones (0,5-2 mm; 2-4 mm; >4 mm) con el fin de recoger los restos botánicos que no han flotado.

\subsection{Modo de conservación}

Los restos arqueobotánicos recuperados en Praileaitz I se han preservado casi exclusivamente por carbonización. Además existe un número pequeño de restos carpológicos que no están carbonizados. La carbonización es un fenómeno que se produce en diferentes fases (CHABAL et al., 1999). Cuando los restos vegetales, alcanzada la temperatura de $500^{\circ}$, no tienen oxigeno suficiente para quemarse por completo, producen restos que se pueden localizar e identificar. Los carbones son, por tanto, el producto de una combustión incompleta, ya que si esta se hubiese completado, el resultado final habrían sido cenizas. En lugar de esto, los componentes orgánicos de la planta se convierten en material rico en carbón y resistente a la descomposición que no se ve afectado por los agentes externos. Esto implica que los carbones localizados en yacimientos arqueológicos son consecuencia de la interrupción, intencionada o accidental, del proceso de combustión (CHABAL et al., 1999). Las causas de esto pueden ser diversas: acumulación de residuos de combustión o acciones mecánicas de origen antrópico que pueden favorecer una mayor formación de brasas (PIQUÉ, 1999).

\subsection{Identificación}

El análisis de los restos se ha realizado en el Laboratorio de Arqueobotánica del Área de Prehistoria de la Universidad del País Vasco/ Euskal Herriko Unibertsitatea (Vitoria-Gasteiz) y en los Laboratorios de Arqueobiología del Instituto de Historia, en el Centro Ciencias Humanas y Sociales (CCHS) del Consejo Superior de Investigaciones Científicas (Madrid). Los restos antracológicos 
se han examinado en un microscopio de luz incidente (50x/100x/200x/500x) en sus secciones transversal, longitudinal radial y longitudinal tangencial. La unidad de base considerada para este estudio es el fragmento de carbón (CHABAL, 1991). Se han analizado todos los carbones $>2 \mathrm{~mm}$, un total de 7455 , repartidos de manera desigual en los contextos mencionados anteriormente. La identificación se ha realizado mediante la comparación de las características anatómicas del material arqueológico con una colección de referencia de maderas modernas, así como con los atlas de anatomía de la madera de Schweingruber (1990), Hather (2000) y Vernet et al. (2001). Las fotografías de la anatomía de las maderas se han realizado con un microscopio electrónico de barrido JSM-6400.

Por otra parte, las identificaciones del material carpológico se han realizado con una lupa binocular. Se han examinado 6 fracciones diferentes $(>4 \mathrm{~mm}, 4-2 \mathrm{~mm}$, $2-1 \mathrm{~mm}, 1-0,5 \mathrm{~mm}, 0.5-0,25 \mathrm{~mm}$ y $<0.25 \mathrm{~mm}$ ) que han facilitado el triado del material recuperado. En todas las muestras se ha estudiado la totalidad de las fracciones.

\section{3.- RESULTADOS}

\subsection{Material antracológico}

Como ya se ha mencionado en el apartado referente al desarrollo del muestreo, se han estudiado un total de 3448 muestras. De estas, en 1189 no se han obtenido resultados. En algunas de ellas, muestras de flotación sobre todo, por no conservar macrorresto botánico alguno. En el caso de los carbones aislados reconocidos durante el transcurso de la excavación, por tratarse de fragmentos de carbón de tamaño $<1 \mathrm{~mm}$, demasiado pequeños para ser identificados. En lo que se refiere al resto de las muestras en las que sí se han obtenido resultados positivos, un gran número de ellas están formadas por un único elemento, por lo que aunque el esfuerzo de recuperación y el volumen de muestras recuperadas ha sido grande, el número de macrorrestos botánicos no lo es tanto. Cabe subrayar que se han identificado todos los fragmentos recuperados, un total de 7455 carbones, de los cuales 31 han resultado no determinables. Se han identificado un mínimo de 8 taxones. Entre las coníferas se identifican Juniperus sp. (enebro, sabina) y Taxus baccata (tejo) y entre las frondosas Alnus sp. (aliso), Corylus avellana (avellano), Ericaceae (ericáceas), Fraxinus sp. (fresno), Prunus sp. (rosáceas) y Quercus subgénero Quercus (incluye todos los Quercus de hoja caducifolia y marcescente que en la actualidad crecen en el País Vasco. Q. petraea-roble albar, Q. robur-pedunculado, Q. pubescens-pubescente, Q. faginea-quejigo, $Q$. pyrenaica-melojo).

Durante la realización de los análisis y en su almacenamiento posterior, se han mantenido las divisiones espaciales por lechos y cuadros realizadas durante la excavación. Sin embargo, para este trabajo y, con el fin de simplificar la interpretación y lectura de los datos, los restos se han unido por niveles cronológicos.

En el vestíbulo se han estudiado un total de 213 muestras, 119 de las cuales han resultado estériles, y un total de 355 carbones. Estos se distribuyen en tres de los seis niveles localizados. El nivel V, el nivel III y el primer nivel, revuelto (0), no cuentan con ningún macrorresto. En el nivel IV (Magdaleniense Inferior) se ha localizado, en un lugar céntrico del vestíbulo, un hogar en cubeta (Fig. 1) datado en $15190 \pm 50$ BP (16694-16104 cal BC) y $15460 \pm 100$ BP (16918-16586 cal BC). Tiene una superficie de unos 1,5 $\mathrm{m}$ de largo por 0,80 de ancho, y se ha estudiado de manera independiente por las características propias con las que cuentan estos tipos de estructuras, aunque tanto en el hogar, como en el resto del nivel, es la madera de enebro/sabina la que domina de manera clara, localizándose casi de forma monoespecífica (>97\%). Junto a esta madera se han identificado algunos fragmentos de rosáceas, Quercus caducifolios y tejo. En los dos niveles más superficiales con macrorrestos (I y II, correspondientes al nivel superficial y Epipaleolítico respectivamente) se produce un gran cambio, ya que es la madera de Quercus caducifolio la que domina, encontrándose un único elemento de ericácea en las muestras del nivel I (Tabl. 2).

Junto al vestíbulo se localiza la galería noroeste. Aquí se han estudiado un total de 5 muestras y 14 carbones, todos recogidos a mano in situ. Una de las muestras no contaba con macrorrestos vegetales. Como se observa en la tabla 3 se ha identificado un número muy reducido de carbones $(n=12)$, siendo la madera de enebro/sabina la que aparece en mayor cantidad seguida de la de Quercus caducifolio (Tabl. 3).

\begin{tabular}{|l|c|c|c|c|c|c|c|}
\hline \multicolumn{7}{|c|}{ PRAILEAITZ I VESTíBULO } \\
\hline \multicolumn{1}{|c|}{ Cronología } & NIVEL & Ericaceae & Juniperus sp. & Prunus sp. & Quercus subg. Quercus & Taxus baccata & TOTAL \\
\hline Nivel superficial & I & 1 & & & 22 & $\mathbf{2 3}$ \\
\hline Epipaleolítico & II & & & & 107 & $\mathbf{1 0 7}$ \\
\hline \multirow{2}{*}{ Magdaleniense Inferior } & IV & & 12 & 1 & 2 & $\mathbf{1 5}$ \\
\cline { 2 - 9 } & IV HOGAR & & 185 & 1 & $\mathbf{1 0}$ & $\mathbf{1 9}$ \\
\hline & TOTAL & $\mathbf{1}$ & $\mathbf{1 9 7}$ & $\mathbf{2}$ & $\mathbf{1 3 3}$ & $\mathbf{2}$ & $\mathbf{3 3 5}$ \\
\hline
\end{tabular}

Tabl. 2. Datos absolutos de los carbones identificados en el vestíbulo de Praileaitz I. / Charcoal absolute data identified in the lobby of Praileaitz I. 


\begin{tabular}{|l|c|c|c|c|c|}
\hline \multicolumn{7}{|c|}{ PRAILEAITZ I GALERÍA NOROESTE } \\
\hline Cronología & NIVEL & Juniperus sp. & Quercus subg. Quercus & TOTAL & No determinable \\
\hline- & $\|$ & & & & 2 \\
\hline- & IV & & 3 & $\mathbf{3}$ & \\
\hline Magdaleniense Inferior & V & 9 & & $\mathbf{9}$ & \\
\hline & TOTAL & $\mathbf{9}$ & $\mathbf{3}$ & $\mathbf{1 2}$ & $\mathbf{2}$ \\
\hline
\end{tabular}

Tabl. 3. Datos absolutos de los carbones identificados en la galería noroeste de Praileaitz I. / Charcoal absolute data identified in the NW gallery of Praileaitz I.

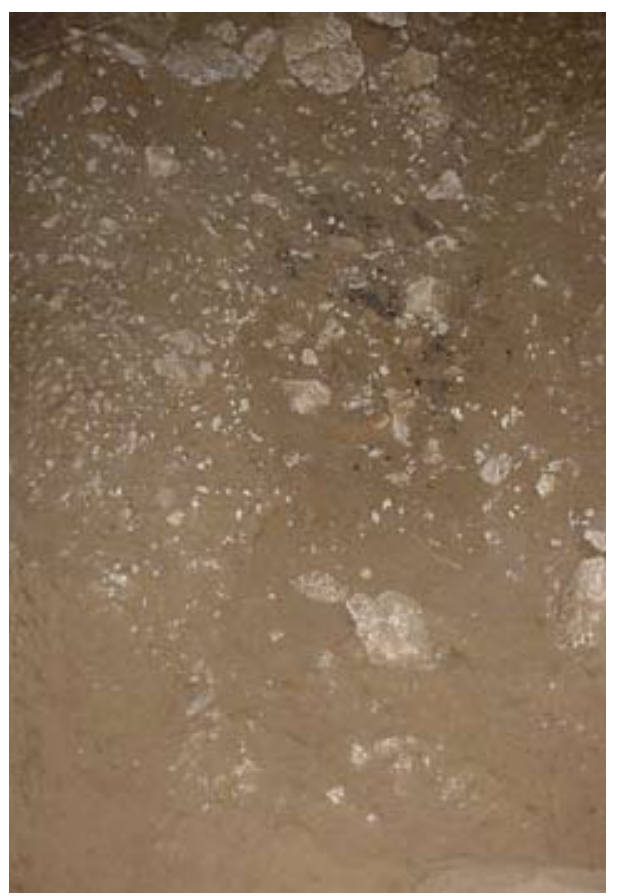

La zona denominada como de tránsito entre el vestíbulo y la primera sala interior o pasillo, presenta características específicas que ha habido que tener en cuenta a la hora de agrupar las muestras analizadas. Este entorno incluye en su mayor parte carbones procedentes de una gran zona de combustión de uso prolongado (nivel II.I, correspondiente al Epipaleolítico -Fig. 2-). Aunque parece que se trata de un único entorno de combustión, se han podido discriminar dos grandes momentos, por lo que se ha optado por dejar las muestras separadas en dos grandes hogares, que podrían ser interpretados como uno solo que se ha desarrollado y crecido en el tiempo (PEÑALVER et al., 2017a). Además de esto, el gran tamaño de las dos estructuras hace que espacialmente una (Hogar 1) se haya introducido en una de las bandas del vestíbulo (Banda A), mientras que el denominado Hogar 2 (8940 \pm 50 BP -8267-7963 cal BC-), de unos $2 \mathrm{~m}$ de diámetro, se extiende a una banda de las de la primera sala interior (Banda D). Esto nos ha obligado a unir parte de los materiales de estas dos bandas localizadas fuera del pasillo (Banda A y Banda D),
Fig. 1. Imagen del hogar en cubeta localizado en el nivel IV (Magdaleniense Inferior) en el vestíbulo. / Picture of the combustion structure located at Level $\checkmark$ (Lower Magdalenian) bucket in the lobby.

con lo identificado en el pasillo, para poder dar mayor coherencia a los niveles que se corresponden con estas estructuras. De igual forma que se ha actuado con el primer hogar descrito en el vestíbulo, se ha actuado con los siguientes, individualizando estas dos estructuras con respecto al resto de los carbones de la zona (Tabl. 4).

En esta zona se han estudiado un total de 1442 carbones, 1437 identificados. El nivel $V$ y más antiguo (Solutrense), está formado únicamente por 2 elementos, y ambos se corresponden con madera de tejo, algo diferente con respecto al resto de los carbones localizados en Praileaitz I. En los niveles IV (Magdaleniense Inferior) y II.II (Epipaleolítico), aunque los carbones de Quercus caducifolios representen más del 98\% del total del nivel, se identifican otros taxones como avellanos (en los dos casos), alisos, o fresnos (en el nivel II.II). En los niveles más superficiales, II.I (Epipaleolítico- la datación se realiza sobre madera carbonizada sin identificar) y I.III, son también Ios Quercus caducifolios los que dominan, representado en estos casos la totalidad de la madera identificada. Esto mismo sucede en los dos hogares identificados, ambos en el nivel II.I. (Tabl. 4).

En las muestras localizadas en la primera sala interior se han estudiado 1632 fragmentos de madera carbonizada de los cuales 1629 han resultado identificados. Los niveles V (Solutrense) y II (Epipaleolítico) están compuestos únicamente por madera de Quercus caducifolio. Esto mismo sucede en las muestras relacionadas con el gran hogar en cubeta (Fig. 3) de esta zona (Las dataciones se han realizado sobre madera carbonizada identificada como Quercus subg. Quercus-8840 \pm 45 BP - 8208-7758 cal BC, $8845 \pm 40$ BP - 8208-7790 cal $\mathrm{BC}$ o como angiosperma no identificable $-9.010 \pm 50 \mathrm{BP}$ - 8300-7984 cal BC), de entre 70 y $80 \mathrm{~cm}$ de diámetro, donde se han estudiado un total de 1183 carbones. El nivel IV (Magdaleniense Inferior) es algo diferente ya que, aunque los Quercus caducifolios dominan de forma clara 


\begin{tabular}{|c|c|c|c|c|c|c|c|c|c|}
\hline \multicolumn{10}{|c|}{ PRAILEAITZ I. ZONA PASILLO } \\
\hline Cronología & NIVEL & $\begin{array}{l}\text { Alnus } \\
\text { sp. }\end{array}$ & $\begin{array}{l}\text { Corylus } \\
\text { avellana }\end{array}$ & Fraxinus sp. & $\begin{array}{l}\text { Quercus } \\
\text { subg. } \\
\text { Quercus }\end{array}$ & $\begin{array}{l}\text { Quercus } \\
\text { sp. }\end{array}$ & $\begin{array}{c}\text { Taxus } \\
\text { baccata }\end{array}$ & TOTAL & $\begin{array}{c}\text { No } \\
\text { determinable }\end{array}$ \\
\hline Nivel superficial & I.III & & & & 103 & & & 103 & 1 \\
\hline \multirow{6}{*}{ Epipaleolítico } & II.I & & & & 27 & 7 & & 34 & \\
\hline & II.I & & & & \multirow{2}{*}{179} & & & \multirow{2}{*}{179} & \\
\hline & HOGAR 1 & & & & & & & & \\
\hline & II.I & & & & \multirow{2}{*}{633} & \multirow{2}{*}{1} & & \multirow{2}{*}{634} & \multirow{2}{*}{1} \\
\hline & HOGAR 2 & & & & & & & & \\
\hline & $\|\|$. & 2 & 1 & 2 & 396 & & & 401 & 2 \\
\hline Magdaleniense Inferior & IV & & 9 & & 36 & & & 45 & 1 \\
\hline Solutrense & V & & & & & & 2 & 2 & \\
\hline \multirow[t]{2}{*}{ - } & SIN NIVEL & & & & 39 & & & 39 & \\
\hline & TOTAL & 2 & 10 & 2 & 1413 & 8 & 2 & 1437 & 5 \\
\hline
\end{tabular}

Tabl. 4. Datos absolutos de los carbones identificados en la zona de tránsito entre el vestíbulo y la primera sala interior o pasillo de Praileaitz I. / Charcoal absolute data identified in the transit area between the lobby and the first inner room or hallway of Praileaitz I.

Fig. 2. Imagen de la zona de combustión localizada en la zona de tránsito entre el vestíbulo y la primera sala interior (o pasillo). / Picture of the combustion zone located in transit between the lobby and the first inner room (or hallway).

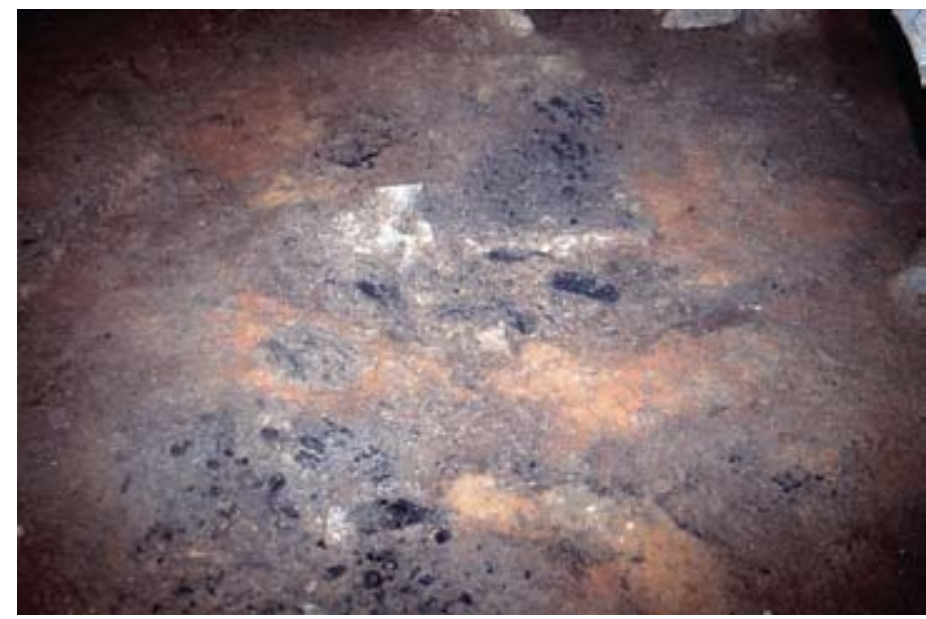

\begin{tabular}{|l|c|c|c|c|c|c|}
\hline \multicolumn{9}{|c|}{ PRAILEAITZ I. PRIMERA SALA INTERIOR } \\
\hline \multirow{2}{*}{ Cronología } & NIVEL & Corylus avellana & Juniperus sp. & Quercus subg. Quercus & TOTAL & No determinable \\
\hline & $\|$ & & & 54 & $\mathbf{5 4}$ & 1 \\
\cline { 2 - 9 } & HOGAR-II & & & 1183 & $\mathbf{1 1 8 3}$ & $\mathbf{7 7}$ \\
\hline Solutrense & IV & 1 & 2 & 74 & $\mathbf{2 9 8}$ & 2 \\
\hline- & V & & & 298 & $\mathbf{1 7}$ & \\
\hline & SIN NIVEL & & & 17 & $\mathbf{1 6 2 9}$ & $\mathbf{3}$ \\
\hline
\end{tabular}

Tabl. 5. Datos absolutos de los carbones identificados en la primera sala interior de Praileaitz I. / Charcoal absolute data identified in the first inner room of Praileaitz I. 


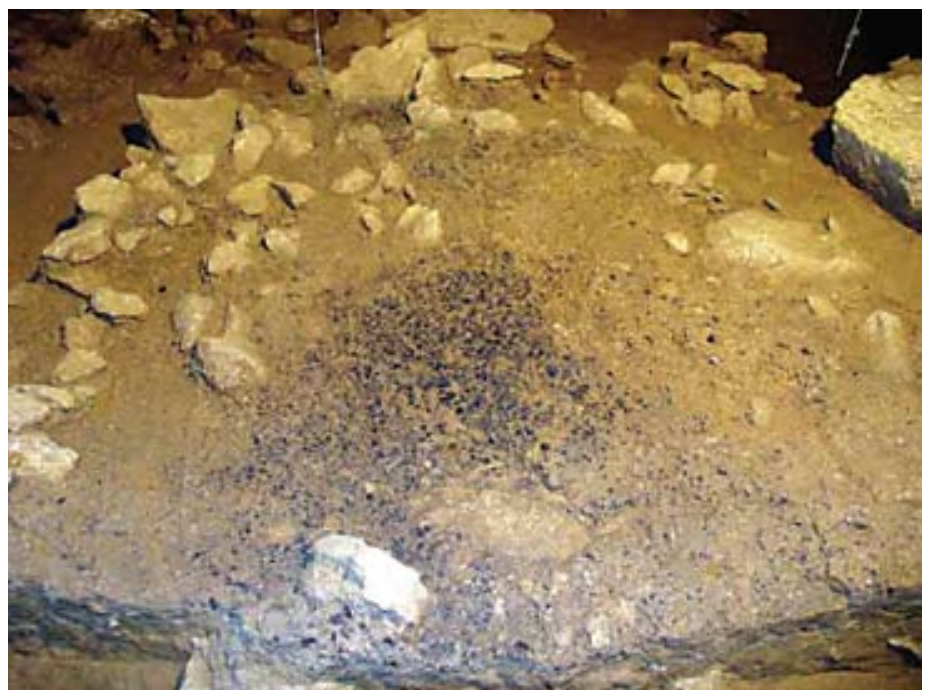

Fig. 3. Detalle del gran hogar en cubeta localizado en la primera sala interior. / Detail of the large combustion structure located in the first inner room bucket.

(96\%), aparecen también algunos fragmentos de madera de avellano o enebro/sabina (Tabl. 5).

La segunda sala interior es el lugar donde se ha recuperado mayor número de carbones (Fig. 4), un total de 4032, de los cuales 4011 han resultado identificables. Para el nivel más antiguo localizado hasta el momento, el IX (Solutrense), se ha recuperado un único fragmento de Quercus caducifolio. Tanto el nivel VIII (datado sobre ma- dera carbonizada identificada como Quercus subg. Quercus: $8985 \pm 45$ BP - 8288-7978 cal BC), VI, V, IV y III (los últimos cuatro niveles correspondientes al Epipaleolítico) poseen una tendencia similar con una preponderancia de la madera de Quercus caducifolio, pero con apariciones puntuales de madera de avellano o enebro/sabina. En el nivel II (Epipaleolítico) se ha recuperado un total de 9 fragmentos de madera, todos Quercus caducifolio (Tabl. 6).

\begin{tabular}{|c|c|c|c|c|c|c|c|c|c|c|c|}
\hline \multicolumn{12}{|c|}{ PRAILEAITZ I. SEGUNDA SALA INTERIOR } \\
\hline Cronología & NIVEL & $\begin{array}{l}\text { Corylus } \\
\text { avellana }\end{array}$ & $\begin{array}{l}\text { cf. } \\
\text { Corylus }\end{array}$ & Juniperus sp. & cf. Juniperus & $\begin{array}{c}\text { Quercus } \\
\text { subg. } \\
\text { Quercus }\end{array}$ & $\begin{array}{c}\text { cf. Quercus } \\
\text { sp. }\end{array}$ & $\begin{array}{l}\text { Ang. } \\
\text { no id. }\end{array}$ & $\begin{array}{c}\text { Gimnos. } \\
\text { no id. }\end{array}$ & TOTAL & $\begin{array}{c}\text { No } \\
\text { determinable }\end{array}$ \\
\hline \multirow{4}{*}{ Epipaleolítico } & $\|$ & & & & & 9 & & & & 9 & \\
\hline & III & 1 & & & 1 & 209 & & & & 211 & \\
\hline & $\mid \mathrm{V}-\mathrm{V}-\mathrm{VI}$ & 30 & 1 & 2 & & 3545 & 2 & 2 & 3 & 3585 & 17 \\
\hline & VIII & 1 & & 5 & 1 & 191 & 1 & & 6 & 205 & 4 \\
\hline \multirow[t]{2}{*}{ Solutrense } & IX & & & & & 1 & & & & 1 & \\
\hline & & 32 & 1 & 7 & 2 & 3955 & 3 & 2 & 9 & 4011 & 21 \\
\hline
\end{tabular}

Tabl. 6. Datos absolutos de los carbones identificados en la segunda sala interior de Praileaitz I. / Charcoal absolute data identified in the second inner room of Praileaitz I.

Con el fin de facilitar la lectura e interpretación de los datos antracológicos, se han unido los resultados procedentes de diferentes zonas de Praileaitz I en las que la estratigrafía se corresponde directamente. Son los carbones localizados en el vestíbulo, pasillo y la primera sala interior. En el caso de las maderas procedentes de la galería noroeste y la segunda sala interior, debido a que estas funcionan de manera independiente con respecto al resto de los lugares estudiados hasta el momento, conteniendo posiblemente carbones procedentes de otras zonas de la cueva, debido a múltiples arrastres de materiales, se han de entender de forma independiente (ver PEÑALVER et al., 2017a). Se pueden resumir los siguientes resultados (Tabl. 7 y Fig. 5):

En el nivel V, Solutrense, datado c. 19330-17530 cal BC domina de manera clara la madera de Quercus caducifolio, con la excepción de 2 únicos fragmentos de madera de tejo.

En el siguiente nivel, el IV, ya en cronologías del Magdaleniense Inferior c. 16700-16100 cal BC, se cuenta con madera dispersa y con un hogar. La madera dominante en las muestras dispersas sigue siendo la de Quercus 


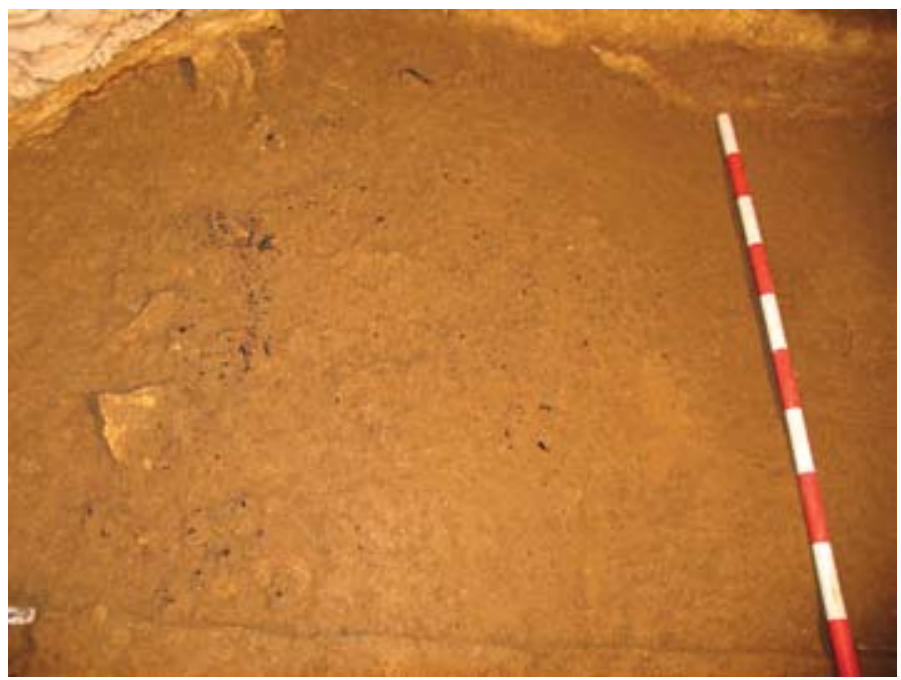

Fig. 4. Imagen de carbones dispersos localizados en la segunda sala interior. / Picture of scattered charcoals located in the second inner room.

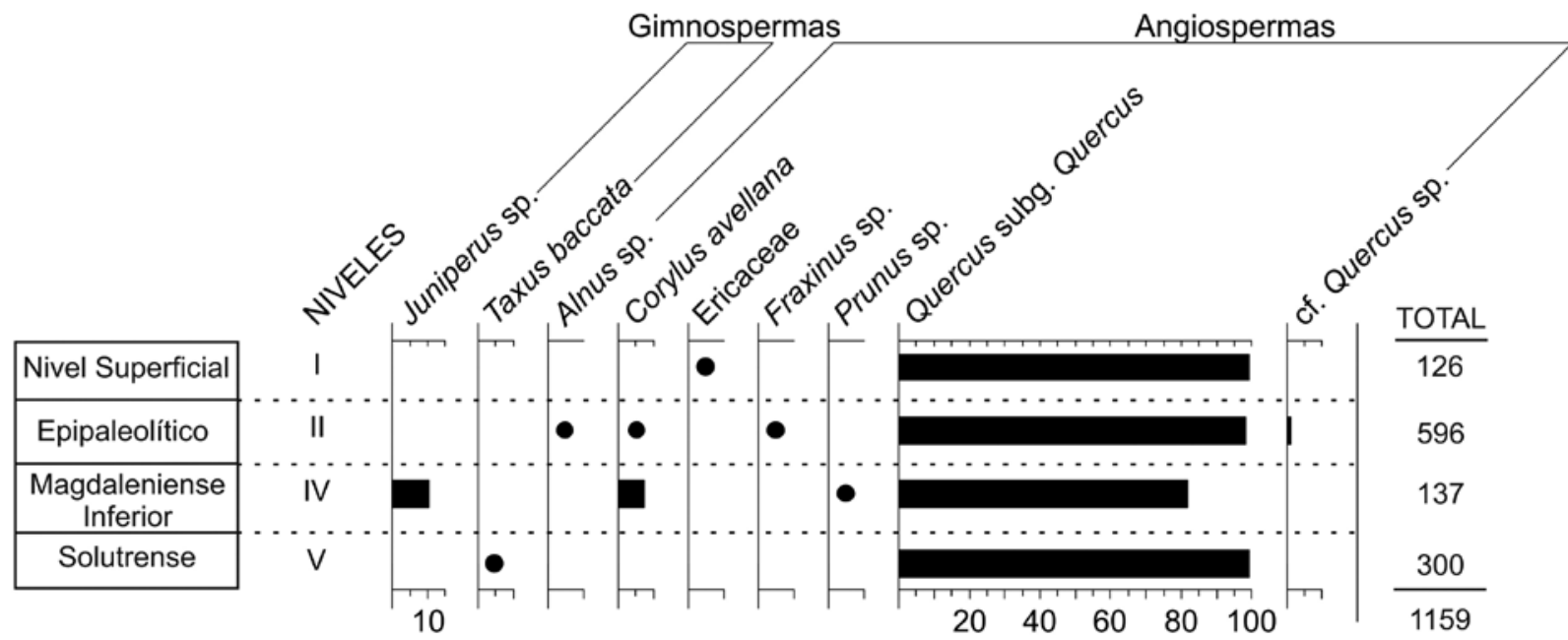

Fig. 5. Datos absolutos de los carbones identificados en la primera sala interior de Praileaitz I. / Charcoal absolute data identified in the first inner room of Praileaitz I.

caducifolio, aunque en este caso se acompaña de otras como enebro, avellano o madera de rosácea tipo Prunus. Curiosamente, el hogar localizado en esta cronología presenta una tendencia totalmente diferente ya que, como se ha comentado anteriormente, la mayoría de la madera del hogar es enebro $(97,4 \%)$. El hecho de que la muestra del hogar sea casi monoespecífica y además de madera de enebro/sabina, un taxón que es excepcional en el yacimiento, abogaría por una corta duración del hogar o al menos reflejaría pocos episodios de combustión.

Para el Nivel III de cronología Magdaleniense Superior-Final no se han conservado macrorrestos vegetales.

En el nivel II, de cronología epipaleolítica, se ha analizado un gran número de carbones $(n=2592)$. Se trata de un periodo en el que durante la excavación se han reconocido tres hogares, que han permitido conservar este gran número de elementos. Es muy interesante el hecho de que los hogares sean monoespecíficos en todos los casos -tan sólo se identifica en ellos madera de Quercus caducifolio a pesar del elevado número de restos identificados-. La madera dispersa -no concentrada en hogares- también se corresponde casi en su totalidad con madera de este taxón. Sin embargo, se han podido documentar además otros taxones como aliso, avellano y fresno, que probablemente señalan la existencia de cierta diversidad arbórea en el entorno de la cavidad, así como la explotación de zonas próximas a cursos de agua.

El nivel I, superficial, sigue la tendencia anterior con una mayoría de madera de Quercus caducifolio, acom- 
pañada de un único fragmento de madera de ericácea, un elemento arbustivo.

\subsection{Material carpológico}

Se han localizado restos carpológicos en un total de 47 muestras. 46 de ellas corresponden a material procesado por flotación y solo una se ha recuperado a mano durante el transcurso de la excavación. Los resultados se observan en la Tabla 8. Como se puede ver, los restos corresponden en su mayoría a material sin carbonizar: semillas de Rubus (género de la mora de zarza) y Sambucus (semillas de saúco). La excepción es un fragmento de pericarpio de avellana (Corylus avellana) localizado en la segunda sala interior (Niveles IV-V y VI) de cronología epipaleolítica.

\section{4.- DISCUSIÓN}

\subsection{La madera carbonizada}

Los carbones localizados en Praileaitz I son residuos generados mediante procesos de combustión de origen antrópico realizados en el yacimiento que, al menos en algunas ocasiones, se han conservado en forma de hogares. Su estudio permite conocer qué especies se utilizaron en la cavidad, y en cierta medida cómo se aprovechó el entorno forestal del yacimiento (UZQUIANO, 1997). Así, el estudio antracológico aporta información sobre las comunidades forestales presentes en el entorno del yacimiento, desde el Solutrense hasta momentos epipaleolíticos, y contribuye a caracterizar las pautas humanas en el aprovisionamiento del combustible. Además, el material antracológico se ha empleado así mismo para caracterizar cronológicamente el depósito en base a dataciones radiométricas. En casi la totalidad de los casos, la madera datada es Quercus caducifolio con la excepción de un fragmento no determinable.

Este estudio abarca diferentes zonas de la cueva en las que se ha desarrollado la intervención arqueológica: el vestíbulo, la galería noroeste, el tránsito entre el vestíbulo y la primera sala interior o pasillo, la primera sala interior y la segunda sala interior. Como se ha comentado anteriormente en el apartado correspondiente a resultados, se han unido aquellos datos antracológicos que, aunque proceden de diferentes lugares de la cueva, su estratigrafía se corresponde directamente (vestíbulo, pasillo y la primera sala interior). Tras la unión por niveles de los resultados de las diferentes localizaciones, como se observa en la Tabla 7 y Figura 5, a pesar del elevado número de fragmentos de madera carbonizada $(n=3345)$, muestras y contextos estudiados, la lista de taxones representados no es muy amplia. Además de ciertos taxones con un reducido número de restos identificados, como son alisos, avellanos, fresnos, tejos, ericáceas y rosáceas, la madera recuperada básicamente se compone de Quercus subgénero Quercus (grupo de

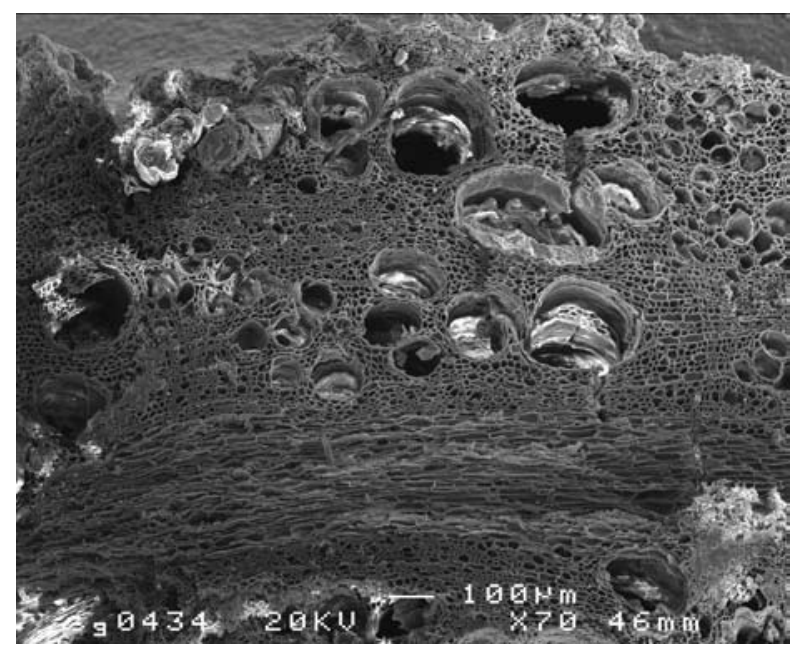

Fig. 6. Sección transversal de Quercus subgénero Quercus (Quercus caducifolio). Cuadro 180' lecho 6. x: 95, y: 76, z: 365. 03/04/2007. / Cross section of Quercus subgenus Quercus (deciduous Quercus). Table 180 'bed 6.x: 95 and: 76, z: 365. 03/04/2007.

los robles caducifolios y marcescentes) a lo largo de toda la secuencia (Fig. 6). Este resultado se da tanto en maderas concentradas, como en los carbones dispersos en el sedimento. Tampoco hay diferencias entre los distintos lugares estudiados. Se ha de comentar como excepción la madera de enebro/sabina en el hogar del nivel IV del vestíbulo, además de diferentes apariciones puntuales.

De igual manera, en las dos salas que tienen una estratigrafía diferenciada del resto del yacimiento, la tendencia es similar. En la segunda sala interior (Tabl. 6), con un gran volumen de madera identificada $(n=4011)$, son los Quercus caducifolios los que dominan de manera clara, con algunos fragmentos de madera de avellano y de enebro/sabina. Los resultados de esta zona se mantienen individualizados debido a que, como ya se ha mencionado en el capitulo pertinente, los sedimentos pueden estar alterados en parte. La datación de diferentes elementos de esta zona ha proporcionado fechas epipaleolitícas para los niveles de I a VIII, pudiendo proceder los carbones directamente del arrastre de los dos grandes hogares del pasillo, o del de la primera sala interior. En el último nivel excavado hasta la fecha (nivel IX) se ha obtenido una datación solutrense (PEÑALVER et al., 2017a). Además se han localizado diferentes fragmentos óseos de tipología mucho más antigua que los carbones, posiblemente por la remoción de los animales visitantes de la cueva, como osos o zorros. La galería noroeste (Tabl. 3), localizada junto al vestíbulo, solo cuenta con 12 elementos identificados de los cuales 3 son de Quercus caducifolio y 9 enebro/sabina (nivel V-Magdaleniense Inferior).

Con los resultados obtenidos en Praileaitz I, debido a la escasa variedad en los taxones identificados, no se aprecian cambios en el uso de sus combustibles, por la gran representación de la madera de Quercus caducifolio. Los datos sobre la dispersión o concentración de los elementos vegetales, nos muestran a los Quercus cadu- 
cifolios como la madera mejor representada en todos los casos, con la excepción del hogar del nivel IV, del Magdaleniense Inferior. Este hogar en cubeta del vestíbulo está en contraposición con lo que ocurre en el resto del yacimiento. Así, se ha preferido la madera de enebro casi de manera monoespecífica, acompañada únicamente por algunos fragmentos $(n=5)$ de Quercus caducifolio, tejo y rosácea.

De manera general, se relaciona a los restos vegetales que aparecen dispersos como procedentes de una acumulación de diferentes limpiezas de actividades domesticas realizadas, como por ejemplo de los hogares, durante procesos de larga duración. Por este motivo, estos carbones representan diferentes recogidas de leña de la vegetación del entorno y la continuidad de la actividad. Así, ofrecen una visión representativa de las formaciones vegetales circundantes, siempre que muestren la totalidad o gran parte de las especies del territorio explotado (CHABAL, 1988). Por el contrario, los restos procedentes de las estructuras concentradas, representan acontecimientos breves en el tiempo, proporcionando, de manera general, poca diversidad de especies, por tratarse de la última madera aportada. Así, la imagen de la vegetación que genera es limitada, con maderas sobrerrepresentadas, que puede ser complementada con los resultados obtenidos en las maderas de origen disperso (CHABAL, 1997; BADAL et al., 2003; CARRIÓN, 2005). La monoespecificidad de los hogares, el correspondiente al Magdaleniense Inferior formado exclusivamente por madera de enebro, y los del pasillo y el de la primera sala interior, por madera de Quercus caducifolio (Tabl. 7), todos ellos del Epipaleolítico, encaja bien con su origen, ya que como se ha comentado anteriormente, los hogares reflejan pocas recogidas de leña, y suelen contener un último episodio de combustión, dejando pocas oportunidades a la diversidad (BADAL, 1987-88, 1988; CHABAL, 1997; NTINOU, 2002; THÉRY-PARISOT et al., 2010: 143). Se tiende a considerar que los carbones concentrados en estructuras de combustión tienen un potencial etnobotánico propio, dejando los dispersos al margen de interpretaciones de este tipo. No obstante, son residuos de las plantas que se han consumido y ésta es la razón por la que se encuentran en los contextos arqueológicos que se estudian (BUXÓ \& PIQUÉ, 2008).

La recolección no siempre está condicionada por la ley del mínimo esfuerzo, según la cual se tendería a invertir el mínimo trabajo en la recolección de los recursos (PIQUÉ, 1999). La estrategia de aprovisionamiento de leña viene determinada por diferentes variables vinculadas a la demanda dependiendo del tipo de asentamiento y de las necesidades del mismo. La demanda también está condicionada por la disponibilidad de especies en el entorno o por las características de las maderas en función de la utilidad que se les va a otorgar (construcción de viviendas, herramientas, leña, cerramientos, etc.) (BUXÓ \& PIQUÉ, 2008).

Se desconoce cuál ha podido ser la función específica de estos hogares, aunque próximos al localizado en el vestíbulo, en la zona más luminosa de la cueva, se han recuperado restos de fauna en conexión anatómica que podrían corresponder con animales en espera de ser consumidos. En los otros hogares no se ha recuperado ningún resto de fauna. El hogar del tránsito entre el vestíbulo y la primera sala interior tiene un gran volumen que ocupa la práctica totalidad de la anchura de la galería y cuando se encontrara encendido impediría el paso entre ambas zonas. El hogar de la primera sala interior es más reducido y está en una zona en la que apenas se dispone de luz natural. Ambos pudieron servir tanto para iluminar el espacio como para proporcionar calor (PEÑALVER, MUJIKA-ALUSTIZA, 2017). Aunque se ha de recordar que el resto de la madera identificada en el yacimiento, la localizada dispersa en los diferentes niveles, también tiene un carácter casi monoespecífico, por la gran importancia de la madera de Quercus caducifolio. Los otros taxones identificados (Alnus sp., Corylus avellana, Ericácea, Fraxinus sp., Prunus sp. y Taxus baccata) tienen una presencia puntual en los diferentes niveles, no siendo ajenos a las principales comunidades forestales presentes potencialmente en el entorno.

Así, la poca variedad de taxones en los análisis de carbones puede deberse a la presencia mayoritaria en su entorno de masas forestales amplias de robledales que ofrecen un combustible de excelente calidad. Quercus subgénero Quercus (roble albar, pedunculado, pubescente, quejigo, melojo) es la madera más abundante en la secuencia del yacimiento. El roble aguanta bien el rigor del invierno ya que tiene una gran resistencia al frío y a las heladas tardías, pero con el calor estival requiere humedad en el suelo. Todos los Quercus ofrecen una leña muy apreciada, muy resistente, elástica y que aguanta muy bien la humedad, tradicionalmente muy utilizada como combustible. La corteza se utiliza como curtiente y sus frutos, las bellotas, son comestibles (LÓPEZ GONZÁLEZ, 1982, 2002; AIZPURU et al., 1990; LÓPEZ LILLO \& SÁNCHEZ DE LORENZO CÁCERES, 1999; ORTIZ, 2006). Juniperus sp. es el taxón dominante en el hogar Magdaleniense, aunque también tiene algunos elementos dispersos. El morfotipo aquí denominado como Juniperus sp. incluye especies y hábitats diversos (AIZPURU et al., 1990) ya que las diferentes especies del género Juniperus no se pueden diferenciar en base a sus características anatómicas (SCHWEINGRUBER, 1978, 1990). En la Península Ibérica incluye J. communis (enebro común), J. oxycedrus (enebro de la miera), J. sabina (sabina rastrera), J. phoenicea (sabina negral) y J. thurifera (sabina albar) (LÓPEZ GONZÁLEZ, 2002). Todas las especies mencionadas, integradas dentro de la denominación Juniperus sp., alcanzan en la actualidad grandes extensiones en la Península Ibérica tanto en ambientes eurosiberianos como mediterráneos (AIZPURU et al., 1990; LÓPEZ GONZÁLEZ, 2002). Se trata de una madera compacta, aromática (utilizada su resina como incienso), de color rojizo, grano fino, densa, muy resistente a la putrefacción y a los cambios bruscos de temperatura que produce grandes llamas y muchas chis- 
pas al quemarse (J. communis) y se utiliza para ahumar (AIZPURU et al., 1990; LÓPEZ LILLO \& SÁNCHEZ DE LORENZO CÁCERES, 1999; ORIA DE RUEDA \& DIEZ, 2003; ORTIZ, 2006; VELASCO SANTOS, 2009).

Esta abundancia de recursos leñosos de gran calidad, reflejados claramente en los carbones estudiados, permitiría, por ejemplo, ignorar o explotar a pequeña escala el bosque de ribera que debería de encontrarse en las cercanías de Praileaitz I, por el transcurrir del río Deba. La madera que se podría obtener allí, como la de aliso o fresno identificada entre los carbones estudiados, es más blanda, de combustión más rápida, de menor porte y no muy longeva, en comparación con la que obtienen con los robles (LÓPEZ GONZÁLEZ, 1982, 2002; AIZPURU et al., 1990; LÓPEZ LILLO \& SÁNCHEZ DE LORENZO CÁCERES, 1999; ORIA DE RUEDA \& DIEZ, 2003; ORTIZ, 2006). También la localización del yacimiento, con respecto al río, en una zona escarpada, como se ha comentado anteriormente, podía dificultar el acceso a estos recursos. Además, se ha de tener en cuenta que los asentamientos en Praileaitz I no parecen alargarse en el tiempo, siendo su carácter esporádico y con un número reducido de individuos (PEÑALVER et al. 2017b), por lo que la madera se tomaría en las inmediaciones de la cueva, rodeadas de forma potencial por amplios bosques de robles, madera que aparece de forma mayoritaria en nuestro estudio.

La existencia de Quercus caducifolios no solo se documenta aquí en Praileaitz I, como se puede ver en los otros estudios de la zona, tanto palinológicos como antracológicos. Estos reflejarían como el Quercus caducifolio se encuentra de forma natural en todo el Pirineo Occidental desde al menos el Pleistoceno Superior, debido fundamentalmente a condicionantes biogeográficos. La deficiente conservación de los palinomorfos detectada en el estudio palinológico llevado a cabo en Praileaitz I (IRIARTE, 2017) no permite contar con una visión de las comunidades vegetales del entorno más o menos cercano del yacimiento. Esto dificulta la realización de comparaciones directas con el análisis antracológico de la cueva, que pudieran resolver la problemática entre la captación de los recursos maderables y el paisaje circundante. A nivel regional, sí que se dispone en la actualidad de otras secuencias paleoambientales que pueden contribuir a una mejor caracterización del medio ambiente (incluyendo el paisaje vegetal) dominante durante las épocas en las que se ocupó la cueva. El Gravetiense (sin restos antracológicos en Praileaitz I) y el inicio de la ocupación Solutrense, se desarrollaron en un momento probablemente frío y sobre todo seco, correspondiente al Greenlan Stadial 3, y que concluye c. 23500 cal BP. Esta fase se ha reconocido por ejemplo en los niveles 5 y 6 , de la cercana cueva de Askondo (GARCÍA-IBAIBARRIAGA et al., 2015) o en Santimamiñe (ROFES et al. 2014). La composición del paisaje vegetal de este momento, cuyo conocimiento es por desgracia muy limitado debido a la escasez de registros y a la esterilidad polínica de muchas secuencias, es similar en todas las secuencias del can- tábrico. En los estudios de La Riera (LEROI-GOURHAN, 1986), Santimamiñe (IRIARTE, 2011) y El Mirón (STRAUS et al., 2011) se señala la existencia de un paisaje abierto, dominado por brezales y vegetación de tipo xerófilo (Artemisia), y con bosques muy reducidos, formados por pinares, junto con enebros y algunos caducifolios, reflejando un deterioro claro de las condiciones climáticas.

Con posterioridad, durante la mayor parte de la ocupación solutrense, desarrollada en Praileaitz I entre c. $23700-21000$ cal BP, las condiciones ambientales parecen ser diferentes. Las secuencias regionales señalan una mejoría clara de las condiciones climáticas, que parecen ser algo más templadas y húmedas, (Greenland Interestadial 2). Esta fase de corta duración (c. 2350022800 cal BP) no es fácil de identificar, y solo es evidente en estudios de alta resolución en secuencias continuas, como en El Pindal (MORENO et al., 2010). Tras esta fase más templada y húmeda, de nuevo se detecta otra fase más seca y posiblemente más fría entre c. 22800-18500 cal BP (primera fase del Greenland Stadial 2). Esta fase está representada en el Nivel 4 de la cueva de Askondo, donde en una cronología de c. 21432-20836 cal BP el registro de micromamíferos señala también una fase adversa, pero no tan fría y árida como la documentada a inicios del MIS 2, con una mayor presencia de los indicadores de bosque (GARCÍA-IBAIBARRIAGA et al., 2015). El paisaje vegetal refleja este recrudecimiento climático, por la presencia de vegetación asociada a episodios fríos y áridos (Artemisia, Chenopodiaceae, Juniperus, etc.). A partir de este momento, c. 18500 cal BP, las condiciones ambientales están mejor descritas, ya que existen más estudios paleobotánicos que contribuyen a un mejor conocimiento del paisaje. Los registros palinológicos disponibles documentan la existencia de un primer evento frío (según autores denominado Dryas antiguo o Dryas I) visible en Ekain (DUPRÉ, 1984), Erralla (BOYER-KLEIN, 1985), Abauntz (LÓPEZ GARCÍA, 1982), Santa Catalina (IRIARTE, 2014) y Santimamiñe (IRIARTE, 2011). Sus secuencias palinológicas evidencian la existencia de una débil cobertura arbórea en la que los pinos y los enebros estaban presentes, junto con algunos caducifolios de manera ocasional. Entre las herbáceas dominan las compuestas, con cierta presencia de elementos estépicos y escasa representación de las esporas de helechos. Desde c. 15000 cal BP se asiste de nuevo a una mejoría muy evidente de las condiciones climáticas, correspondiendo con el Greenland Interestadial 1 (Gl-1) En la reconstrucción paleoclimática de Santimamiñe (ROFES et al., 2014) se señala que desde c. $12790 \pm 70$ BP (15551-15036 cal BP) el ambiente era notablemente más templado que con anterioridad, posiblemente reflejo de la oscilación Bolling/Allerod. En esta fase, desde c. 15400 cal BP el espeleotema de El Pindal reanuda su crecimiento, posiblemente como reflejo de una fase más templada y sobre todo con una mayor disponibilidad de agua (MORENO et al., 2010). En Ekain (DUPRÉ, 1984), durante el Magdaleniense Final (Nivel Vla), se manifiesta esta mejoría climática, lo mismo que en Erralla (BOYER- 
KLEIN, 1985). En estos momentos la cobertura arbórea era superior a la documentada en las fases frías, con presencia tanto de pinares como de taxones caducifolios, además de con esporas de helechos, evidenciando un clima más atemperado y húmedo.

Tras el final del Tardiglaciar, caracterizado como se ha descrito, por cierta variabilidad climática en base a la sucesión de períodos fríos y templados, se ha detectado el inicio de una fase marcada por el incremento general de las temperaturas y las precipitaciones. Los estudios palinológicos disponibles para los inicios del Holoceno, señalan como principal característica una importante colonización arbórea tras los últimos episodios fríos del Tardiglaciar. En el Pirineo Occidental, estos bosques estaban principalmente compuestos por formaciones caducifolias, en las que los avellanos, quercíneas, abedules, tilos, etc, tenían una destacada presencia. También se han documentado notables evidencias de la presencia de cursos de agua relativamente estables, por la aparición de importantes cortejos vegetales riparios (aliso, sauce, olmo, etc), como reflejo de la mayor disponibilidad hídrica asociada a esta nueva fase climática. Otra formación que se documenta en prácticamente todas las regiones es la de los pinares. En general, su reducida presencia porcentual en los diagramas palinológicos, unido a su elevada tasa de producción y dispersión polínica (LOPEZ SÁEZ et al., 2013), sugieren que no debieron constituir bosques dominantes en la mayoría del territorio del País Vasco. Sin embargo en el área pirenaica adquieren un mayor desarrollo, posiblemente por tratarse de una zona montañosa más adaptada a sus requerimientos ecológicos. Todo esto se puede observar en los registros estudiados a lo largo del Pirineo Occidental, como en los depósitos naturales de la Reserva de la Biosfera de Urdaibai (IRIARTE et al., 2006b), Playaundi (SÁNCHEZ GOÑI, 1996), y en los arqueológicos de Kobeaga II (IRIARTE, 2000), Pareko Landa (IRIARTE et al., 2006a, 2007/2008), El Mirón (IRIARTE, 2012), Arenaza I (ISTURIZ \& SÁNCHEZ GOÑI, 1990), Ekain (DUPRÉ, 1984), Urtiaga (SÁNCHEZ GOÑI, 1993), Aizpea (IRIARTE, 2001) o Padre Areso (IRIARTE et al., 2007/2008).

En lo referente al aprovisionamiento de madera documentado en este período, en el Pirineo Occidental, el primer comentario ha de centrarse en la escasez de registros. Además, en algunos estudios el número de carbones analizado es muy escaso, insuficiente para extraer datos concluyentes sobre explotación forestal, aunque sí son útiles, como se ha mencionado anteriormente, para observar presencia de determinados taxones. Este es el caso de la cueva de Antoliña, donde se hace una mención somera sobre el estudio antracológico, señalando que "el combustible utilizado en el yacimiento podría definir una secuencia en la que se suceden periodos muy fríos, dominados por formaciones arbustivas y de coníferas, con otros más templados" (análisis realizado por L. Zapata, citado en LOZANO et al., 2002, pp 197). En el estudio de Azkonzilo, con cronologías del Solutrense Antiguo, Medio y Superior, se observa cómo es la madera de Juniperus la más abundante. Junto a ella también los Quercus caducifolios tienen una gran importancia. Otros taxones reflejan porcentajes más reducidos como Abies alba, Salix sp., Alnus glutinosa o Castanea sativa. La autora sugiere un clima frío debido a la abundancia de los enebros (UZQUIANO, 1992). En el yacimiento de Santa Catalina se recoge una sucesión de tres niveles arqueológicos con ocupaciones que coinciden con las etapas finales del Tardiglaciar con complejos tecno-industriales adscritos al Magdaleniense Superior, Final y Aziliense. Aquí, la presencia recurrente de fuegos y estructuras de combustión ha permitido la conservación de abundantes restos de madera. En el nivel más antiguo se refleja la existencia de un paisaje vegetal en el que están presentes las coníferas (pino y enebro) junto a la madera de madroño y algunos elementos arbustivos, lo que podría reflejar la persistencia de una vegetación preforestal con elementos típicos de condiciones frías del último Máximo Glacial. En el Magdaleniense Final se apunta el uso abundante de la madera de abedul (Betula), respondiendo a su probablemente extensión como elemento pionero en la expansión de los bosques durante el Tardiglaciar. Disminuyen las coníferas y el madroño en favor de los Quercus. En el Aziliense se refleja la expansión del uso del robledal y del encinar (RUIZ-ALONSO et al., 2014).

En la cueva de Santimamiñe el estudio antracológico para las cronologías más antiguas se realiza sobre un número de carbones reducido (siempre inferior a 90 fragmentos). En todos los niveles de cronología magdaleniense estudiados (Magdaleniense Inferior Medio/Superior y Superior/Final), es la madera de enebro la mejor representada junto a otros taxones como leguminosa, aliso, abedul, pino, Quercus sp., entre otros. En el nivel de cronología aziliense, se observa un cambio importante, aunque los resultados se han de tomar con cautela debido al reducido número de carbones estudiados. Aquí es ahora la madera de Quercus caducifolio la mejor representada, localizándose un número muy reducido de carbones de enebro, junto con madera de abedul y rosáceas (EUBA REMENTERIA, 2011). No lejos de la anterior se localiza la cueva de Laminak II. El estudio antracológico, se realiza sobre un número de carbones escaso, ya que se tiene en cuenta solo aquellos que se corresponden con la zona no afectada por furtivos. Se estudian los dos niveles magdalenienses de forma independiente, aunque en ambos, se refleja un bosque caducifolio con abundancia de Quercus acompañado de otras especies de hoja perenne o caducifolia observándose, según la autora, un progresivo atemperamiento a lo largo de la secuencia estratigráfica (UZQUIANO, 1994).

Ya para los inicios del Holoceno, se dispone de yacimientos como Kobeaga II, donde para el nivel identificado como Mesolítico Geométrico, dominan los Quercus caducifolios frente al resto de taxones, como Quercus perennifolios, avellanos, madroños, fresnos, pomoideas, chopos/sauces, siempre con valores más reducidos (ZAPATA, 2000a). En el yacimiento de Santimamiñe se ha localizado un hogar mesolítico en el que se ha identificado 
en su mayoría fragmentos de Quercus, junto con rosáceas y algunos elementos no identificables (EUBA REMENTERIA, 2011). En la cueva de El Mirón, en el estudio antracológico de esta misma cronología, se refleja una preponderancia casi absoluta entre la madera recolectada de Quercus caducifolios, además, se han identificado de manera testimonial madera de avellano y rosácea (ZAPATA, 2012). Ya en el área pirenaica, en el estudio antracológico de Aizpea (ZAPATA, 2001), se puede observar cómo el combustible utilizado ha variado con el tiempo a lo largo del VII milenio cal BC. En la fase más antigua se ha quemado madera de árboles mesófilos como olmo, aliso, abedul, fresno, arce, roble y avellano. Sin embargo son la madera de endrino y los espinos (Rhamnus) componentes muy importantes en la muestra. La fase intermedia se caracteriza por el mayor uso de la madera de roble, aunque siguen presentes gran parte de las otras especies como endrino, avellano o fresno.

Observando estos datos y en comparación con los estudios palinológicos se puede apuntar que, en cualquier caso, y aunque se produjera una selección humana de combustibles específicos, los espectros antracológicos son coherentes con la situación ambiental y vegetal del Tardiglaciar que se refleja en los estudios palinológicos. De forma general, las maderas más explotadas son las de coníferas como los pinos o enebros, acompañadas por algunos taxones caducifolios como quercíneas o avellanos, todos ellos presentes en las cercanías de los depósitos. Para cronologías epipaleolíticas, la madera carbonizada localizada en los yacimientos se ajusta al patrón de la vegetación que indican los análisis palinológicos, aunque con una preferencia por la madera de caducifolios, en la mayoría de los casos representados por madera Quercus, con pequeñas apariciones de la de avellano. En el caso concreto de Praileaitz I en base a los resultados obtenidos en la madera carbonizada identificada, se puede sugerir la existencia en el entorno de un bosque mesófilo compuesto fundamentalmente por quercíneas caducifolias, acompañadas por avellanos y algún tejo disperso. A ellos les acompañaría una orla arbustiva en la que se localizarían las ericáceas y las rosáceas. Enebro/sabina estaría situado en las zonas con suelos menos desarrollados y secos, de mayor insolación. En la zona cercana al río Deba, podrían encontrarse los alisos y los fresnos, característicos de estos entornos húmedos. La escasa variabilidad taxonómica de la madera localizada en los diferentes niveles cronológicos (niveles del Solutrense, del Magdaleniense Inferior y Epipaleolítico), debido a la amplia representación del combustible de Quercus caducifolio, mostraría una continuidad, en lo que al paisaje vegetal se refiere, a lo largo de la secuencia estudiada. Es decir, pocos cambios en el entorno vegetal de la cueva. Esto puede deberse en parte a la oferta del entorno o a la especial tipología del yacimiento, en el que se localizan grandes hogares que concentran una gran cantidad de carbones, siendo ocupaciones de corta duración, etc. Del mismo modo, la madera podría reflejar pocos cambios en la forma en la que se explota el entorno de la cueva, seleccionando de forma generalizada los Quercus caducifolios.

\subsection{La alimentación vegetal: semillas y frutos}

Los restos de alimentación vegetal son extremadamente escasos en los yacimientos de cazadores-recolectores del sur de Europa. En Praileaitz I se ha realizado un enorme esfuerzo por intentar recuperarlos, procesando grandes cantidades de sedimento mediante flotación. Sin embargo, se concluye que el sedimento de Praileaitz I prácticamente no incluye macrorrestos vegetales carbonizados que no sean madera. Los resultados carpológicos han sido escasos y la mayoría de los restos localizados no están carbonizados. En nuestra opinión es muy poco probable que estos materiales no carbonizados sean prehistóricos ya que no es habitual que existan formas de conservación diferentes a esta en yacimientos pleistocenos o epipaleolíticos en cueva en el sur de Europa. Sin embargo, en yacimientos históricos, por ejemplo de cronología medieval, es habitual recuperar Rubus y Sambucus no carbonizados y en ocasiones se ha asumido que pueden tener un origen arqueológico y presentar una conservación diferencial frente a otros materiales botánicos. Resumiendo el caso de Praileaitz I, se interpreta que lo más probable es que se trate de intrusiones recientes o subactuales, observándose además que la mayoría de ellos (c. 97\%) se localizan en el nivel superficial del vestíbulo, pero realmente la única forma de confirmarlo sería mediante una datación radiométrica. La excepción es un fragmento de cáscara de avellana carbonizado que se ha localizado en la segunda sala interior (Niveles IV-V y VI) de cronología epipaleolítica. La avellana es el alimento vegetal más abundante en los yacimientos holocenos vascos de cazadores-recolectores (ZAPATA, 2000b). Independientemente de que se tratara de un recurso muy abundante durante este periodo, como puede observarse en los trabajos palinológicos (IRIARTE et al., 2007, 2008), es probable que de hecho esté sobrerrepresentada en nuestros yacimientos ya que el tejido de su cáscara arde muy bien, es denso y resistente, aunque en el caso de Praileaitz I, como se ha comentado anteriormente, únicamente se ha localizado un fragmento. El hecho de que se encuentre carbonizado sugiere en Praileaitz I que se trata de un resto de origen antrópico, que podría haber formado parte de la alimentación de los habitantes de la cueva o haber venido incorporado en una de las ramas utilizadas como combustible. Se quiere subrayar que existieron en el entorno de la cueva recursos vegetales comestibles que se conoce han sido utilizados por los grupos cazadores-recolectores europeos, en concreto la bellota (Quercus spp.) y los frutos de Prunus (grupo del endrino y cerezo silvestres).

La escasez de restos carpológicos en la cavidad puede deberse a factores diversos, no excluyentes que ya se ha señalado para otros yacimientos cazadores-recolectores (ZAPATA \& PEÑA-CHOCARRO, 2005: 418): 
1) Escasez original en el consumo o utilización de materias vegetales: las actividades realizadas en el sitio condicionan los subproductos antrópicos que se generan. La recolección y el consumo de vegetales pudieron no llevarse a cabo en el lugar, al menos con una intensidad y unas características que permitieran su reconocimiento arqueológico. Tampoco se han recuperado en el abrigo útiles relacionados con el consumo o procesado de alimentos vegetales (cantos rodados con impacto para romper avellanas, por ejemplo),

2) Estacionalidad, si la ocupación de la cueva no coincide con las épocas del año en que se recogen los frutos con mayor visibilidad arqueológica (final del verano-otoño),

3) La ausencia de carbonización de los recursos vegetales. A pesar de que los fuegos han existido -ya que se tiene en Praileaitz I madera carbonizada y estructuras de hogar- los productos vegetales que se consumieron o utilizaron no se procesaron necesariamente en contacto con el fuego o no resistieron el contacto con el fuego,

4) La destrucción postdeposicional del material, ya que las semillas en particular son muy frágiles frente al daño mecánico y se conoce mal los efectos físico-químicos que el sedimento puede tener en la preservación de los materiales.

Resumiendo los factores que influyen en la formación del registro arqueobotánico algunas veces se re- lacionan con las actividades humanas allí desarrolladas mientras que otras son estrictamente tafonómicos. La interpretación deberá realizarse a la luz de otras evidencias arqueológicas.

\section{5.- CONCLUSIONES}

La madera carbonizada recuperada en Praileaitz I corresponde a un largo periodo que se extiende desde el Solutrense c. 17530 - 19330 cal BC hasta al menos el Epipaleolítico c. 8600-7900 cal BC. El número de fragmentos de madera $>2 \mathrm{~mm}$ analizado en el yacimiento es elevado $(n=7455)$ por lo que se piensa que la muestra refleja bien el contenido antracológico de la matriz sedimentaria. Los restos se han conservado de dos formas, concentrados en hogares y dispersos. Independientemente del origen, la interpretación general es que existe un uso continuado de madera de Quercus subgénero Quercus en todas las unidades. Quercus caducifolio se reconoce en todos los contextos, en general con porcentajes superiores al $80 \%$, e igual o próximo al 100\% en otros casos (Tabl. 7). La única excepción consiste en un hogar magdaleniense que prácticamente sólo contiene madera de enebro/sabina (Juniperus sp.).

A partir de estos resultados, se puede concluir que no existen evidencias significativas para poder concretar si en Praileaitz I existe una diferenciación en el uso de los contextos y de las maderas utilizadas en ellos. Más bien es al contrario, las similitudes son muy altas y los taxones

\begin{tabular}{|c|c|c|c|c|c|c|c|c|c|c|c|c|}
\hline $\begin{array}{l}\text { Adscripción } \\
\text { cronocultural }\end{array}$ & NIVEL & $\begin{array}{l}\text { Alnus } \\
\text { sp. }\end{array}$ & $\begin{array}{l}\text { Corylus } \\
\text { avellana }\end{array}$ & Ericaceae & $\begin{array}{c}\text { Fraxinus } \\
\text { sp. }\end{array}$ & $\begin{array}{c}\text { Juniperus } \\
\text { sp. }\end{array}$ & $\begin{array}{c}\text { Prunus } \\
\text { sp. }\end{array}$ & $\begin{array}{l}\text { Quercus } \\
\text { subg. } \\
\text { Quercus }\end{array}$ & $\begin{array}{c}\text { cf. } \\
\text { Quercus } \\
\text { sp. }\end{array}$ & $\begin{array}{c}\text { Taxus } \\
\text { baccata }\end{array}$ & TOTAL & $\begin{array}{c}\text { No } \\
\text { determinable }\end{array}$ \\
\hline nivel superficial & I & & & $1 / 0,8 \%$ & & & & $125 / 99,2 \%$ & & & 126 & 1 \\
\hline \multirow{4}{*}{ Epipaleolítico } & II & $2 / 0,3 \%$ & $1 / 0,2 \%$ & & $2 / 0,3 \%$ & & & $584 / 98 \%$ & $7 / 1,2 \%$ & & 596 & 3 \\
\hline & II-HOGAR 1 & & & & & & & $179 / 100 \%$ & & & 179 & \\
\hline & II-HOGAR 2 & & & & & & & $633 / 99,8 \%$ & $1 / 0,2 \%$ & & 634 & 1 \\
\hline & II-HOGAR & & & & & & & $1183 / 100 \%$ & & & 1183 & \\
\hline \multirow{2}{*}{$\begin{array}{l}\text { Magdaleniense } \\
\text { Inferior }\end{array}$} & IV & & $10 / 7,3 \%$ & & & $14 / 10,2 \%$ & $1 / 0,7 \%$ & $112 / 81,8 \%$ & & & 137 & 3 \\
\hline & IV HOGAR & & & & & $185 / 97,4 \%$ & $1 / 0,5 \%$ & $2 / 1 \%$ & & $2 / 1 \%$ & 190 & \\
\hline Solutrense & v & & & & & & & $298 / 99,4 \%$ & & $2 / 0,6 \%$ & 300 & \\
\hline
\end{tabular}

Tabl. 7. Datos absolutos y porcentuales agrupados por niveles (excepto galería noroeste y segunda sala interior). / Absolute data and percentages grouped by levels (except NW and second inner gallery room). 
más significativos están representados de forma similar en todos los contextos y en los diferentes momentos cronológicos. Praileaitz I es un ejemplo excelente de la escasa diversidad taxonómica que suelen presentar los hogares arqueológicos. Las muestras que podrían caracterizar depósitos sintéticos, resultado de actividades de larga duración u ocupaciones prolongadas en el tiempo, suelen tener mayor diversidad ya que reflejan recogidas de leña múltiples que en sí mismas son un muestreo de la vegetación. En estos casos, en Praileaitz I, además de Quercus caducifolio se ha identificado tejo (Taxus baccata), enebro/sabina (Juniperus sp.) y rosáceas (Prunus sp.) en los periodos antiguos Solutrense y Magdaleniense Inferior, mientras que aliso (Alnus), fresno (Fraxinus sp.), y brezo (Ericácea) aparecen en las muestras holocenas. El avellano (Corylus avellana) se identifica de forma importante $(7,3 \%)$ en el Magdaleniense Inferior y se documenta también en el Epipaleolítico.

La escasa diversidad taxonómica y la posible sobrerrepresentación de Quercus que se observa en Praileaitz I -a pesar del elevado número de restos identificado- sugiere la existencia de ocupaciones cortas que no dan lugar a recogidas recurrentes de leña que, por acumulación, tenderían a representar mejor un paisaje vegetal que se asume era más variado. Si se excluyen los hogares, destaca la mínima diversidad del nivel solutrense (99,4\% de roble).

Los resultados del estudio palinológico no aportan datos significativos al respecto, debido a una deficiente conservación polínica. En lo que respecta a otros estudios arqueobotánicos del Pirineo Occidental, en los momentos más antiguos de ocupación de la cueva (Gravetiense, Solutrense y Magdaleniense) se observa una variabilidad climática notable, oscilando entre condiciones frías y secas y otras más húmedas y térmicas, algo que se refleja igualmente en las leñas seleccionadas. Ya en el Epipaleolítico se identifican mayores extensiones de bosques caducifolios, algo que se manifiesta igualmente en la madera quemada, con una preferencia significativa por la madera de Quercus caducifolio, como se refleja también en el texto que aquí se presenta.

Así mismo, la aparición de un único fragmento de cáscara de avellana, un recurso habitualmente bien representado en los yacimientos vascos, apoya la idea de que el consumo y procesado de alimentos vegetales no fue en este yacimiento una actividad habitual. No se debe descartar la idea de que este fragmento podría haber venido acompañando a la madera, debido a esa mínima representación.

\section{6.- AGRADECIMIENTOS}

En el momento de redacción de este texto Lydia Zapata formaba parte del Grupo de Investigación del Gobierno Vasco IT622-13/UFI 11-09 de la Universidad del País Vasco/Euskal Herriko Unibertsitatea y del Proyecto del Plan Nacional de I+D HAR 2011-23716. El trabajo se

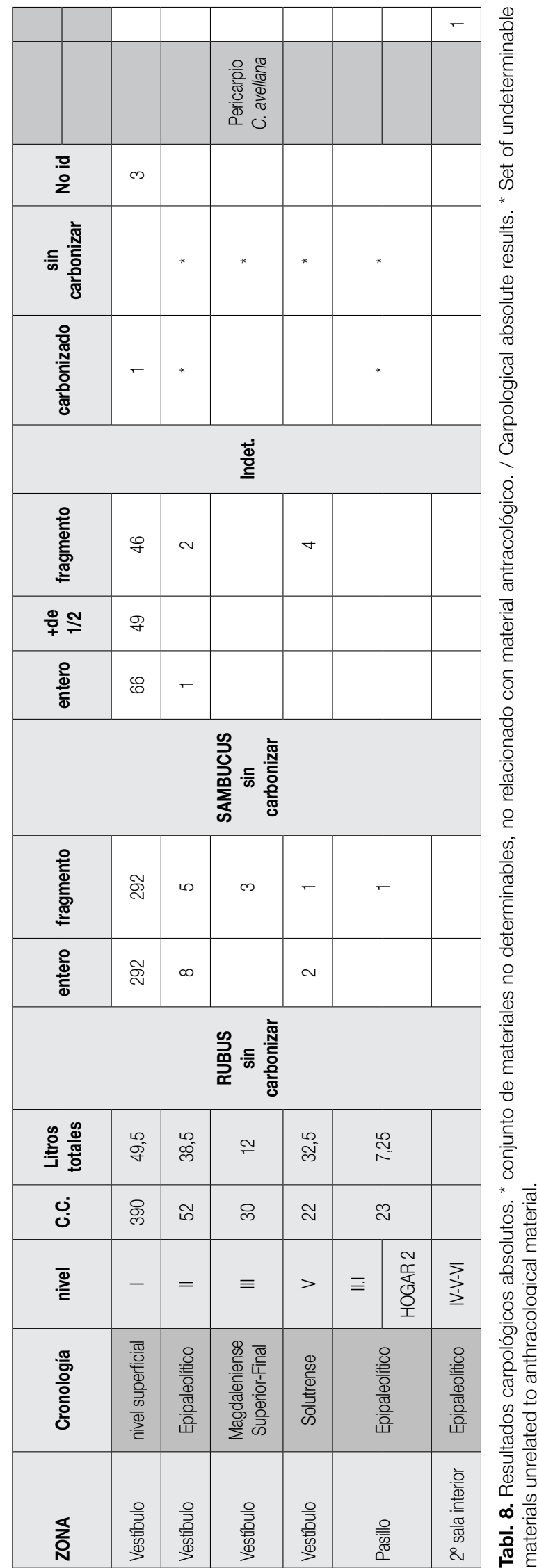


integra en el proyecto ERC_2013_CoG_614960. Queremos agradecer a los responsables de la excavación y estudio interdisciplinario de Praileaitz I el enorme esfuerzo realizado por recuperar los macrorrestos vegetales.

\section{7.- BIBLIOGRAFÍA}

AIZPURU, I., CATALÁN, P., GARIN, F.

1990 Guía de los árboles y arbustos de Euskal Herria. Gobierno Vasco. Vitoria-Gasteiz.

ALONSO MARTÍNEZ, N.

1999 De la llavor a la farina. Els processos agrícoles protohistòrics a la Catalunya Occidental. CNRS. Lattes. (Monographies d'Archéologie Méditerranéenne ; 4).

ALONSO MARTÍNEZ, N., JUAN TRESSERRAS, J., RODRÍGUEZARIZA Y M.O., ROVIRA BUENDÍA, N.

2003 Muestreo arqueobotánico de yacimientos al aire libre y en medio seco, en BUXÓ R. \& PIQUÉ, R. (Dir). La recogida de muestras en arqueobotánica: objetivos y propuestas metofológicas. La gestión de los recursos vegetales y la transformación del paleopaisaje en el Mediterráneo occidental. 29-46. Museu d'Arqueologia de Catalunya. Barcelona.

ASEGINOLAZA, C., GÓMEZ, D., LIZAUR, X., MONTSERRAT, G. MORANTE, G., SALAVERRIA, M.R., URIBE-ECHEVARRIA, P.M.

1992 Mapa de vegetación de la Comunidad Autónoma del País Vasco. Gobierno Vasco. Vitoria-Gasteiz.

BADAL, E.

1987-88 La antracología. Método de recogida y estudio del carbón prehistórico. Saguntum. Papeles del laboratorio de Arqueología de Valencia 21, 169-182.

1988 Resultados del estudio antracológico de la cova de les cendres (Alicante, España). Actas do Encontro "Paleoecologia e Arqueología". Cámara Municipal. Vila Nova de Famalicão.

BADAL, E., CARRIÓN, Y., RIVERA, D., UZQUIANO, P.

2003 La Arqueobotánica en cuevas y abrigos: objetivos y métodos de muestreo, en BUXÓ, R. \& PIQUÉ, R. (Dir). La recogida de muestras en arqueobotánica: objetivos y propuestas metofológicas. La gestión de los recursos vegetales y la transformación del paleopaisaje en el Mediterráneo occidental. 17-27. Museu d'Arqueologia de Catalunya. Barcelona

BOYER-KLEIN, A.

1985 Analyse pollinique de la Grotte d'Erralla. Munibe (Antropologia-Arkeologia) 37, 45-48.

BUXÓ, R.

1990 Metodología y técnicas para la recuperación de restos vegetales (en especial referencia a semillas y frutos) en yacimientos arqueológicos. Ajuntament de Girona. Girona. (Cahier Noir; 5).

1997 Arqueología de las plantas. Crítica. Barcelona.
BUXÓ, R., PIQUÉ, R. (DIR.)

2003 La recogida de muestras en arqueobotánica: objetivos y propuestas metofológicas. La gestión de los recursos vegetales y la transformación del paleopaisaje en el Mediterráneo occidental. Museu d'Arqueologia de Catalunya. Barcelona

BUXÓ, R., PIQUÉ, R

2008 Arqueobotánica. Los usos de las plantas en la península ibérica. Ariel. Barcelona.

CARRIÓN, Y.

2005 La vegetación mediterránea y atlántica de la Península Ibérica. Nuevas secuencias antracológicas. Serie Trabajos Varios del Servicio de Investigación Prehistórica 104. Valencia.

CHABAL, L

1988 Pourquoi et comment prélever les charbons de bois pour la période antique: les méthodes utilisées sur le site de Lattes (Hérault). Lattara 1, 187-222.

1991 L'homme et l'évolution de la végétation méditerranéenne, des âges de métaux à la période romaine: Recherches anthracologiques théoriques, apliques principalement à des sites du Bas Languedoc. Thèse Physiologie et Biologie des Organismes et des Populations. U.S.T.L. Montpellier.

1997 Forêts et sociétés en Languedoc (Néolithique final, Antiquité tardive). L'anthracologie, méthode et paléoécologie. Éditions de la Maison des Sciences de l'Homme. Paris.

CHABAL, L., FABRE, L., TERRAL J.-F., THERY-PARISOT, I.

1999 La Anthracologie, en FERDIERE, A. (Dir.) La Botanique. 43-104. Errance. Paris.

DE MOULINS, D.

1996 Sieving experiment: the controlled recovery of charred plant remains from modern and archaeological samples. Vegetation History and Archaeobotany 5, 153-156.

DUPRÉ, M.

1984 El yacimiento prehistórico de la cueva de Ekain (Deba Guipúzcoa). Palinología de los niveles VII a II, en ALTUNA, J. \& MERINO, J.M., El yacimiento prehistórico de la cueva de Ekain (Deba, Guipúzcoa). 61-63. Sociedad de Estudios Vascos. San Sebastián.

EUBA REMENTERIA, I.

2011 Explotación de los recursos leñosos y reconstrucción de la vegetación desde el tardiglaciar hasta el holoceno en la cueva de Santimamiñe (Kortezubi, Bizkaia), en LÓPEZ QUINTANA, J.C. (Dir.). La cueva de Santimamiñe: revisión y actualización (2004-2006). 267-279. (Kobie. Serie excavaciones arqueológicas en Bizkaia; 1).

GARCÍA IBAIBARRIAGA, N., ROFES, J., BAILON, S., GARATE, D. RIOZ, J., MARTíNEZ GARCÍA, B., MURELAGA, X.

2015 A palaeoenvironmental estimate in Askondo (Bizkaia, Spain) using small vertebrates. Quaternary International $364,244-154$ 
HATHER, J. G.

2000 The identification of the Northern European woods. A guide for archaeologists and conservators. Archetype Publications. Londres.

IRIARTE, M.J.

2000 Estudio palinológico de la cueva de Kobeaga II. Illunzar 4, 171-172.

2001 El entorno vegetal de los pobladores prehistóricos de Aizpea: Análisis polínico, en BARANDIARÁN MAESTU, I. \& CAVA, A. (Eds). Cazadoresrecolectores en el pirineo navarro. El sitio de Aizpea entre 8000 y 6000 años antes de ahora. Veleia, Anejos Serie Mayor 10, 315-324.

2011 Polen y vegetación en la secuencia estratigráfica de Santimamiñe (Kortezubi, Bizkaia), en LÓPEZ QUINTANA, J.C. (Dir.). La cueva de Santimamiñe: revisión y actualización (2004-2006). 321-341. (Kobie. Serie excavaciones arqueológicas en Bizkaia, 1).

2012 The vegetational contexts of El Miron cave throughout the Early to Middle Holocene, en STRAUS, L.G. \& GONZÁLEZ MORALES, M.R. (Eds.). El Miron cave. Cantabrian Spain. The site and its Holocene archaeological record. 119142. University of New Mexico. Alburquerque.

2014 El Tardiglaciar en la cueva de Santa Catalina (Lekeitio, Bizkaia). Evaluación del medio vegetal a través del registro polínico, en BERGANZA GOCHI, E. \& ARRIBAS PASTOR, J.L. (Coords.). La Cueva de Santa Catalina (Lekeitio, Bizkaia). I -La intervención arqueológica. Restos vegetales, animales y humanos. Kobie. Serie excavaciones arqueológicas en Bizkaia, 4. 59-74.

2017 Praileaitz I (Deba, Gipuzkoa): el estudio paleopalinológico, en PEÑALVER, X., SAN JOSE, S., MUJIKA-ALUSTIZA, J.A. La cueva de Praileaitz I (Deba, Gipuzkoa, Euskal Herria). Intervención arqueológica 2000 - 2009. Munibe Monographs. Anthropology and Archaeology Series 1, 193-199.

IRIARTE, M.J., AGIRRE, M., LÓPEZ QUINTANA, J.C., ZAPATA, L. 2006a Poblamiento y paisaje vegetal en Urdaibai durante el pleistoceno superior y los inicios del holoceno, en CADIÑANOS, J.A., IBABE, A., LOZANO, P., MEAZA, G. \& ONAINDIA M. (Eds.). Actas del III Congreso Español de Biogeografía. 107-112. Reserva de la Biosfera de Urdaibai, Servicio de Publicaciones del Gobierno Vasco.

IRIARTE, M.J., MUÑOZ SOBRINO, C., GOMEZ ORELLANA, L., RAMIL REGO, P.

2006b Dinámica del paisaje en la Reserva de la Biosfera de Urdaibai durante el Holoceno, en CADIÑANOS, J.A., IBABE, A., LOZANO, P., MEAZA, G. \& ONAINDIA M. (Eds.). Actas del III Congreso Español de Biogeografía. 113-117. Reserva de la Biosfera de Urdaibai, Servicio de Publicaciones del Gobierno Vasco.

IRIARTE, M. J., PÉREZ DÍAZ, S., RUIZ-ALONSO, M., ZAPATA, L. 2007-2008 Paleobotánica del Epipaleolítico y Mesolítico vascos. Veleia 24-25 (1), 629-642.
ISTURIZ, M.J., SÁNCHEZ GOÑI, M.F.

1990 Investigaciones palinológicas en la prehistoria vasca. Munibe Antropologia-Arkeologia 42, 277-286.

LEROI-GOURHAN, A.

1986 The palynology of La RieraCave, in L.G. STRAUS G.A. CLARK (Ed.). La Riera Cave. 59-64. Arizona State University. Tempe. (ASU Anthropological Research Papers; 36).

LÓPEZ GARCÍA, P.

1982 Abauntz, análisis polínico. Trabajos de Arqueología Navarra 2, 355-358.

LÓPEZ GONZÁLEZ, G

1982 La guía de Incafo de los árboles y arbustos de la Península Ibérica. Incafo. Madrid.

2002 Los árboles y arbustos de la Península Ibérica e Islas Baleares. Mundi-Prensa. Madrid.

LÓPEZ LILLO, A., SÁNCHEZ DE LORENZO CÁCERES, J. M.

1999 Árboles de España: Manual de identificación. Mundi Prensa. Madrid.

LÓPEZ-SÁEZ, J.A., SÁNCHEZ-MATA, D., ALBA-SÁNCHEZ, F., ABEL SCHAAD, D., GAVILÁN, R.G., PÉREZ-DÍAZ, S.

2013 Discrimination of Scots pine forests in the Iberian Central System (Pinus sylvestris var. iberica, Pinaceae) by means of pollen analysis. Phytosociological considerations. Lazaroa 34, 191-208.

LOZANO VALENCIA, P., MEAZA RODRÍGUEZ, G., CADIÑANOS AGUIRRE, J.A.

2002 Paleobiogeografía cultural de la Reserva de la Biosfera de Urdaibai Vizcaya). Boletín de la Asociación de Geógrafos Españoles 34, 193-211.

MARINVAL, PH.

1986 Recherches expérimentales sur l'acquisition des données en Paleocarpologie, Revue d'Archéométrie 10, 57-68.

MORENO, A., STOLL, H., JIMÉNEZ SÁNCHEZ, M., CACHO, I., VALERO GARCÉS, B., ITO, E., EDWARDS, R.L.

2010 A speleothem record of glacial (25-11.6 kyr BP) rapid climatic changes from northern Iberian Peninsula. Globalk and Planetary Change 71, 218-231.

NTINOU, M

2002 La Paleovegetación en el Norte de Grecia desde el Tardiglaciar hasta el Atlántico. Formaciones vegetales, recursos y usos. Hadrian Books. Oxford. (BAR International Series; 1038).

ORTIZ, I (DIR.)

2006 Atlas ilustrado de árboles de España. Susaeta. Madrid.

ORIA DE RUEDA, J.A., DÍEZ, J.

2003 Guía de árboles y arbustos de Castilla y León. Cálamo. Palencia. 
PEÑALVER, X., MUJIKA-ALUSTIZA, J.A.

2017 La utilización del espacio en la ocupación de la cueva de Praileaitz I (Deba, Gipuzkoa), en PEÑALVER, X., SAN JOSE, S., MUJIKA-ALUSTIZA, J.A. La cueva de Praileaitz I (Deba, Gipuzkoa, Euskal Herria). Intervención arqueológica 2000 2009. Munibe Monographs. Anthropology and Archaeology Series 1, 121-133.

PEÑALVER, X., SAN JOSE, S., MUJIKA-ALUSTIZA, J.A.

$2017 a$ El yacimiento arqueológico de Praileaitz I (Deba, Gipuzkoa). Metodología de la excavación, estratigrafía, estructuras y dataciones arqueológicas, en PEÑALVER, X., SAN JOSE, S., MUJIKA-ALUSTIZA, J.A. La cueva de Praileaitz I (Deba, Gipuzkoa, Euskal Herria). Intervención arqueológica 2000 - 2009. Munibe Monographs. Anthropology and Archaeology Series 1, 33-120.

2017b Análisis de la ocupación humana de la cueva de Praileaitz I (Deba, Gipuzkoa): Paleolítico Superior y Epipaleolítico, en PEÑALVER, X., SAN JOSE, S., MUJIKA-ALUSTIZA, J.A. La cueva de Praileaitz I (Deba, Gipuzkoa, Euskal Herria). Intervención arqueológica 2000 - 2009. Munibe Monographs. Anthropology and Archaeology Series 1, 531-541.

PIQUE, R.

1999 Producción y uso del combustible vegetal: una evaluación arqueológica. Treballs d'Etnoarqueologia 3. Universitat Autònoma de Barcelona, CSIC. Madrid.

ROFES, J., MURELAGA, X., MARTíNEZ GARCÍA, B., BAILON, S., LÓPEZ QUINTANA, J.C., GUENAGA LIZASU, A., ORTEGA, L.A., ZULUAGA, M.C., ALONSO, A., CASTAÑOS UGARTE, P., CASTAÑOS, J.

2014 The long paleoenvironmental sequence of Santimamiñe (Bizkaia, Spain): 20,000 years of small mammal record from the latest Late Pleistocene to the middle Holocene. Quaternary International 339-340, 62-75.

RUIZ-ALONSO, M., UZQUIANO, P., ZAPATA, L.

2014 Macrorrestos vegetales de Santa Catalina (Lekeitio, Bizkaia): Carbones y bellotas del Tardiglaciar, en BERGANZA GOCHI, E. \& ARRIBAS PASTOR, J.L. (Coords.). La Cueva de Santa Catalina (Lekeitio, Bizkaia). I-La intervención arqueológica. Restos vegetales, animales y humanos. 75 92. Bizkaiko Foru Aldundia-Diputación Foral de Bizkaia. Bilbao. (Kobie. Serie excavaciones arqueológicas en Bizkaia; 4).

SÁNCHEZ GOÑI. M.F.

1993 De la taphonomie pollinique à la reconstitution de l'environnement. L'example de la région cantabrique. Oxford. (British Archaeological Repports, International Series; 586).

1996 Vegetation and sea level changes during the Holocene in the estuary of the Bidasoa. Quaternaire 7(4), 207-219.

SCHWEINGRUBER, F.H.

1978 Mikroskopische Holzanatomie. Swiss Federal Institute of Forestry Research. Birmensdorf.
1990 Anatomie europäischer Hölzer: ein Atlas zur Bestimmung europäischer Baum-, Strauch- und Zwergstrauchhölzer (Anatomy of European woods an atlas for the identification of European trees shrubs and dwarf shrubs). Verlag P. Haupt. Bern.

STRAUS, L.G., GONZÁLEZ MORALES, M.R., GUTIERREZ ZUGASTI, I., IRIARTE CHIAPUSSO, M.J.

2011 Further Solutrean evidence in El Mirón Cave (Ramales de la Victoria, Cantabria). Munibe Antropologia-Arkeologia 62, 117-133.

THÉRY PARISOT, I., CHABAL, L., CHRZAVZEZ, J.

2010 Anthracology and taphonomy, from wood gathering to charcoal analysis. A review of the taphonomic processes modifying charcoal assemblages in archaeological contexts. Palaeogeography, Palaeoclimatology, Palaeoecology 291(1-2), 142-153.

UZQUIANO, P.

1992 Recherches anthracologiques dans le sec-teur Pyréneocantabrique (Pays Basque, Cantabria et Asturias): en-vironnements et relations homme-milieu au Pléistocène supérieur et début de l'Holocène. Tesis doctoral. Université de Montpellier II.

1994 Estudio antracológico de Laminak \|I (Berriatua, Bizkaia) Kobie. Paleoantropología 21, 167-172.

1997 Antracología y método: implicaciones en la economía prehistórica, etnoarqueología y paleoecología. Trabajos de Prehistoria 54, 145-154.

VELASCO SANTOS, J. M.

2009 Guía de Plantas Útiles y Perjudiciales en Castilla y León. Tempora Ediciones. Salamanca.

VERNET, J.L., OGEREAU, P., FIGUEIRAL, I., MACHADO, C., UZQUIANO, C.

2001 Guide diidentification des charbons de bois préhistoriques et récents. Sud-Ouest de l'Europe: France, Péninsule Ibérique et Îles Canaries. CNRS Éditions. Paris.

WAGNER, G. E.

1988 Comparability among recovery techniques, en HASTORF, C.A. \& POPPER, V.S (Eds.) Current Paleoethnobotany: Analytical Methods and Cultural Interpretations of Archaeological plan remains. 17-35. The University of Chicago Press. Chicago.

ZAPATA L

2000a Análisis de los macrorrestos vegetales de Kobeaga II: la explotación del bosque, Illunzar 4, 177-183

2000b La recolección de plantas silvestres en la subsistencia mesolítica y neolítica. Complutum 11, 157-169.

2001 El uso de los recursos vegetales en Aizpea (Navarra, Pirineo occidental): la alimentación, el combustible y el bosque, en BARANDIARÁN, I. \& CAVA, A. (Eds.). Cazadoresrecolectores en el Pirineo navarro. El sitio de Aizpea entre 8000 y 6000 años antes de ahora. 325-359. UPV/EHU. Vitoria-Gasteiz. (Veleia. Anejos Series Maior 10). 
2012 Holocene wood charcoal from El Miron cave. Vegetation and wood use, en STRAUS, L.G. \& GONZÁLEZ MORALES, M.R. (Eds.). El Mirón cave. Cantabrian Spain. The site and its Holocene archaeological record. 174-196. University of New Mexico. Alburquerque.

ZAPATA, L., PEÑA-CHOCARRO, L.

2005 Los macrorrestos vegetales del yacimiento de Mendandia, en ALDAY, A. (Ed.). El campamento prehistórico de
Mendandia: ocupaciones mesoliticas y neoliticas entre el 8500 y el 6400 B.P. Colección Barandiarán 9, 411-425. Fundación J.M. Barandiarán/Diputación Foral de Álava. Vitoria-Gasteiz.

2013 Macrorrestos vegetales arqueológicos, en GARCÍA DIEZ, M., ZAPATA, L. (Eds.) Métodos y Técnicas de análisis y estudio en arqueología prehistórica. De lo técnico a la reconstrucción de los grupos humanos. 303-314. Servicio Editorial de la Universidad del País Vasco. Billbo. 
